\title{
Overfeeding a moderate energy diet prepartum does not impair bovine subcutaneous adipose tissue insulin signal transduction and induces marked changes in peripartal gene network expression ${ }^{1}$
}

\author{
P. Ji, ${ }^{\star 2}$ J. S. Osorio, ${ }^{\star}$ J. K. Drackley, ${ }^{\star} \dagger$ and J. J. Loor ${ }^{\star} \dagger^{3}$ \\ ${ }^{*}$ Department of Animal Sciences, and \\ †Division of Nutritional Sciences, University of Illinois, Urbana 61801
}

\section{ABSTRACT}

Mechanisms regulating subcutaneous adipose tissue (SAT) insulin sensitivity and gene network expression during the peripartal period were evaluated in cows fed to meet or exceed prepartal energy requirements. Holstein cows were dried off at $-50 \mathrm{~d}$ relative to expected parturition and fed a controlled-energy diet $[\mathrm{CON}$; net energy for lactation $=1.24 \mathrm{Mcal} / \mathrm{kg}$ of dry matter (DM); $36 \%$ of DM as wheat straw] until $-21 \mathrm{~d}$. Cows were then randomly assigned $(\mathrm{n}=7 /$ diet $)$ to either the same CON diet or a moderate-energy close-up diet $(\mathrm{OVE}$; net energy for lactation $=1.47 \mathrm{Mcal} / \mathrm{kg}$ of DM) until parturition. Biopsies of SAT were harvested at $-10,7$, and $21 \mathrm{~d}$ for mRNA expression of 48 genes associated with insulin signaling, adipogenesis, and lipolysis. In vitro basal and insulin-stimulated insulin receptor substrate 1 tyrosine phosphorylation (IRS1PY) was assessed at -10 and $7 \mathrm{~d}$. The OVE led to more positive energy balance and greater serum insulin concentration prepartum. Compared with CON, OVE led to a more drastic increase in serum NEFA and also greater overall serum BHBA postcalving, both of which were associated with greater hepatic total lipid and triacylglycerol concentration. Close-up OVE did not improve any aspect of performance. In prepartal SAT, insulin-stimulated IRS1-PY was greater in OVE than in CON. However, IRS1-PY, serum insulin, and GLUT4 expression decreased postpartum regardless of prepartal treatment, suggesting a more severe state of insulin resistance. The expression of all genes encoding adipogenic regulators (PPARG and ZFP423), most lipogenic enzymes/inducers (FASN, SCD, DGAT2, and INSIG1), and basal-lipolysis regulators ( $A T G L$ and $A B D H 5)$ was greater at $-10 \mathrm{~d}$ in OVE than in

Received October 22, 2011

Accepted March 19, 2012.

${ }^{1}$ Supported by Hatch funds under project ILLU-538-326 (National Institute of Food and Agriculture, Washington, DC).

${ }^{2}$ Current address: Miner Research Institute, 1034 Miner Farm Road PO Box 100, Chazy, NY 12921.

${ }^{3}$ Corresponding author: jloor@illinois.edu
CON. Whereas adipogenic and basal lipolysis regulator expression remained greater in cows fed OVE by $7 \mathrm{~d}$ postpartum, expression of all lipogenic enzymes decreased regardless of diet. Despite those responses, the approximately 3 -fold increase in expression of IRS 1 and ZFP423 between 7 and $21 \mathrm{~d}$ suggested that insulin responsiveness and adipogenic capacity of SAT were partially restored. Expression of the preadipocyte marker DLK1, adiponutrin (PNPLA3), and fibroblast growth factor 21 (FGF21) was undetectable. Results suggested that close-up energy overfeeding did not exacerbate insulin resistance in SAT. Signs of restored insulin responsiveness (upregulation of IRS1, INSIG2, $S R E B F 1$, and ZFP423) were apparent as early as 3 wk postpartum. Thus, identifying specific nutrients capable of activating PPAR $\gamma$ after calving in AT might help accelerate its replenishment. A regulatory network encompassing the genes and physiological measurements obtained is proposed.

Key words: adipose tissue, insulin signaling, lipolysis, dietary energy

\section{INTRODUCTION}

Insulin resistance (IR) has been defined as either decreased sensitivity (the insulin concentration to induce half-maximal response) or responsiveness (the maximal response) of insulin-sensitive tissues [primarily adipose tissue (AT) and skeletal muscle] to insulin (Kahn, 1978). The peripartal period in ruminants has long been thought to represent a physiological state of peripheral IR, and considered an important homeorhetic adaptation to the onset of lactation (Bauman and Currie, 1980). Besides the hypoinsulinemia during early lactation, the apparent IR in AT is linked with a sharp increase in circulating NEFA, particularly after parturition (Bell, 1995). Overmobilization of AT stores is one of the major causes of metabolic disorders postpartum including ketosis and fatty liver (Drackley et al., 2001).

The underlying molecular mechanisms associated with peripartal IR remain largely unknown. Vernon and Taylor (1988) observed compromised insulin sensitivity 
in AT of lactating compared with dry sheep, which could not be attributed to changes in receptor number or insulin-receptor binding affinity; they suggested the possibility of postreceptor defects, which have not been evaluated in ruminants. Tyrosine phosphorylation (PY) of insulin receptor substrates (IRS) is the first step initiating intracellular insulin signal transduction. Accumulating evidence from rodent and human studies has revealed that a defect in tyrosine PY of insulin receptor substrate 1 (IRS1-PY) is causal of peripheral IR either during late pregnancy (Sevillano et al., 2007) or in cases of obesity-induced type II diabetes (Esposito et al., 2001; Sesti et al., 2001). Hence, the IRS1-PY state in AT could be used as a key parameter to assess IR in AT of peripartal dairy cows.

Dry cow diets have been examined as a way to improve feed intake, energy balance, metabolic profiles, and health during the transition period. The steam-up dietary approach during the last few weeks of gestation (i.e., feeding a higher-energy diet primarily by increasing cereal grains) has been used in the field for several years. However, studies from different research groups demonstrated that prepartal overfeeding of energy with greater NFC has often resulted in prepartal hyperglycemia and hyperinsulinemia and marked adipose tissue mobilization (i.e., greater blood NEFA concentration) at the initiation of lactation (Rukkwamsuk et al., 1999; Holtenius et al., 2003; Janovick et al., 2011). As a consequence, energy-overfed cows often have greater hepatic lipid accumulation and are more susceptible to metabolic disorders postpartum (Dann et al., 2006; Janovick et al., 2011). Together, these observed signs provide some evidence that overfeeding energy during the dry period can affect prepartal IR and probably alters lipid metabolism of AT, of which the carryover effects can persist into early lactation.

The hypotheses that we sought to test in the present research were that prepartal energy overfeeding exacerbates IR in subcutaneous AT (SAT) by impairing 1) tyrosine phosphorylation of IRS-1 and altering 2) expression of genes encoding the major adipogenic transcription regulators and enzymes involved in lipogenesis and lipolysis. Specific objectives were to examine the basal and insulin-stimulated phosphorylation state of IRS-1 and corresponding changes in the expression of 48 genes.

\section{MATERIALS AND METHODS}

\section{Experimental Design, Diet, and Animals}

All procedures were conducted under protocols approved by the University of Illinois Institutional Ani- mal Care and Use Committee. Fourteen multiparous Holstein cows were used in this study. All cows were dried off at $\mathrm{d}-50$ relative to expected parturition and fed a controlled-energy diet $\left(\mathrm{NE}_{\mathrm{L}}=1.24 \mathrm{Mcal} / \mathrm{kg}\right.$ of DM; Table 1) containing wheat straw at $36 \%$ of DM for ad libitum intake during the far-off dry period (i.e., d -50 to $\mathrm{d}-21$ ). During the close-up period (i.e., $\mathrm{d}-21$ to parturition), cows were randomly assigned either to a moderate-energy diet $\left(\mathbf{O V E} ; \mathrm{NE}_{\mathrm{L}}=1.47 \mathrm{Mcal} / \mathrm{kg}\right.$ of DM) or continuously fed the same controlled-energy diet $(\mathbf{C O N})$ for ad libitum intake. The same lactation $\operatorname{diet}\left(\mathrm{NE}_{\mathrm{L}}=1.65 \mathrm{Mcal} / \mathrm{kg}\right.$ of $\left.\mathrm{DM}\right)$ was provided for all animals postpartum until 30 DIM.

\section{Management, Sampling, and Analyses}

Complete details are presented in the Supplemental Materials (available online at http://www.journalofdairyscience.org/). Briefly, cows were housed in a freestall barn with Calan gates (American Calan Inc., Northwood, NH) during the dry period (dry-off at $-50 \mathrm{~d}$ relative to expected parturition). At $3 \mathrm{~d}$ before expected parturition, cows were moved to individual maternity pens in the same barn until parturition. After parturition, cows were housed in a tie-stall barn and milked 3 times daily. Prepartal and postpartal diets were fed as a TMR (Table 1). Energy balance was calculated pre- and postpartum individually for each cow based on the equations from NRC (2001; see details in the Supplemental Materials, available online at http:// www.journalofdairyscience.org/).

Blood was sampled from the coccygeal vein or artery every Monday and Thursday before the morning feeding from -21 to $30 \mathrm{~d}$. Samples were collected into evacuated serum tubes containing clot activator (BD Vacutainer; BD and Co., Franklin Lakes, NJ). Serum was obtained by centrifugation at $1,300 \times g$ for $15 \mathrm{~min}$ and frozen at $-20^{\circ} \mathrm{C}$ until later analysis. Serum insulin concentration was analyzed with a commercial bovine insulin ELISA kit (catalog \#10-1201-01; Mercodia AB, Uppsala, Sweden). Concentrations of BHBA and NEFA were analyzed using commercial kits at the Veterinary Diagnostics Laboratory, College of Veterinary Medicine, University of Illinois (Urbana).

\section{SAT and Liver Biopsy and Tissue Handling}

Complete details are presented in the Supplemental Materials (available online at http://www.journalofdairyscience.org/). Briefly, SAT biopsies were collected before the morning feeding from alternate sides of the tail-head region at $-10,7$, and $21 \mathrm{~d}$. Adipose tissue $(2$ to $4 \mathrm{~g}$ ) was collected by blunt dissection. The incision 
was then closed with surgical staples (Multi-Shot Disposable Skin Stapler; Henry Schein, Melville, NY) and iodine ointment was applied to the wound. A portion of tissue was snap frozen in liquid $\mathrm{N}_{2}$ until RNA extraction. The remaining tissue was prepared for culture by quickly rinsing in prewarmed $\left(\sim 37^{\circ} \mathrm{C}\right)$ sterile $1 \times$ PBS solution and coarsely minced to minimize risk of hypoxia. Liver biopsy was conducted as described previously (Dann et al., 2006). Additional details can be found in the Supplemental Materials (available online at http://www.journalofdairyscience.org/).

\section{SAT Explants and Protein Assay}

Complete details are presented in the Supplemental Materials (available online at http://www.journalofdairyscience.org/). Briefly, tissue was carefully processed under a laminar flow hood to remove adjacent nonadipose tissue, chopped into small pieces of ca. $10 \mathrm{mg}$, and placed into sterile Petri dishes (catalog \#5662-7161; Fisher Scientific, Pittsburgh, PA). Samples were then transferred into 12-well culture plates (catalog \#CLS3512; Sigma-Aldrich, St. Louis, MO), which contained $1.5 \mathrm{~mL}$ of $37^{\circ} \mathrm{C} 1 \times$ Dulbecco's modified Eagle's medium (DMEM) in each well. Tissue was preincubated in a water-jacketed $\mathrm{CO}_{2}$ incubator (at $37^{\circ} \mathrm{C}$ with $5 \% \mathrm{CO}_{2}$ ) for $30 \mathrm{~min}$ for adaptation. After 30 min of adaptation, 2 samples were removed and served as duplicate negative controls (i.e., the 0-min sample before insulin challenge). The remaining samples were transferred into a new culture plate, which contained $1.5 \mathrm{~mL}$ of $37^{\circ} \mathrm{C} 1 \times \mathrm{DMEM}$ in each well with or without addition of $1 \mu \mathrm{mol} / \mathrm{L}$ bovine insulin (catalog \#I0516, Sigma-Aldrich; $10 \mathrm{mg} / \mathrm{mL}$ of bovine insulin in $25 \mathrm{mM}$ HEPES, pH 8.2, sterile-filtered). Culture plates were then incubated in the same conditions as listed above. Duplicate samples with or without insulin were removed from plates at 15, 30, and 60 min of incubation.

After removal, tissue samples were immediately immersed into $1.5 \mathrm{~mL}$ of ice-cold $1 \times$ cell lysis buffer (catalog \#9803; Cell Signaling Technology Inc., Danvers, MA) containing $1 \mathrm{~m} M$ phenylmethylsulfonyl fluoride (PMSF; protease inhibitor, catalog \#P7626; SigmaAldrich) and were quickly homogenized. Then, tissue was sonicated in an ice bath 2 times for ca. $10 \mathrm{~s}$ each time to break down the nuclear membrane. Samples were then centrifuged at $8,984 \times g$ at $4^{\circ} \mathrm{C}$ for $10 \mathrm{~min}$ and the supernatant was carefully transferred into 1.5$\mathrm{mL}$ tubes without disturbing the lipid layer, and stored at $-80^{\circ} \mathrm{C}$ until protein analysis.

Total protein was analyzed with the BCA protein assay kit (Cat. \#23227; Thermo Scientific, Fairmont, NJ). Total IRS-1 and IRS-1 pan-tyrosine phosphoryla-
Table 1. Ingredient and chemical composition of diets

\begin{tabular}{|c|c|c|c|}
\hline \multirow[b]{2}{*}{ Component } & \multicolumn{3}{|c|}{$\operatorname{Diet}^{1}$} \\
\hline & $\mathrm{CON}$ & OVE & Lactation \\
\hline \multicolumn{4}{|l|}{ Ingredient ( $\%$ of $\mathrm{DM})$} \\
\hline Alfalfa silage & 12.00 & 8.20 & 5.00 \\
\hline Alfalfa hay & - & 3.50 & 4.00 \\
\hline Corn silage & 33.00 & 35.90 & 33.00 \\
\hline Wheat straw & 36.00 & 15.40 & 4.00 \\
\hline Cottonseed & - & - & 3.50 \\
\hline Wet brewers grains & - & 6.00 & 10.00 \\
\hline Ground shelled corn & 4.00 & 13.00 & 22.20 \\
\hline Soy hulls & 2.00 & 4.00 & 4.00 \\
\hline Soybean meal, $48 \% \mathrm{CP}$ & 7.94 & 3.10 & 3.30 \\
\hline Expeller soybean meal ${ }^{2}$ & - & 2.00 & 6.20 \\
\hline SoyChlor $^{3}$ & 0.15 & 3.80 & - \\
\hline Blood meal $85 \%$ & 1.00 & 1.00 & 0.30 \\
\hline Urea & 0.45 & 0.30 & 0.14 \\
\hline Rumen-inert fat ${ }^{4}$ & - & - & 1.00 \\
\hline Limestone & 1.30 & 1.30 & 1.18 \\
\hline Salt (plain) & 0.32 & 0.30 & 0.27 \\
\hline Sodium bicarbonate & - & - & 0.75 \\
\hline Potassium carbonate & - & - & 0.10 \\
\hline Calcium sulfate & - & - & 0.10 \\
\hline Dicalcium phosphate & 0.12 & 0.18 & 0.27 \\
\hline Magnesium oxide & 0.21 & 0.08 & 0.14 \\
\hline Magnesium sulfate & 0.91 & 0.97 & - \\
\hline Mineral-vitamin $\operatorname{mix}^{5}$ & 0.20 & 0.20 & 0.20 \\
\hline Vitamin $\mathrm{A}^{6}$ & 0.015 & 0.015 & - \\
\hline Vitamin $\mathrm{D}^{7}$ & 0.025 & 0.025 & - \\
\hline Vitamin $\mathrm{E}^{8}$ & 0.38 & 0.38 & - \\
\hline Biotin & - & 0.35 & 0.35 \\
\hline DM of $\operatorname{diet}^{9}(\%)$ & $47.1 \pm 2.0$ & $46.6 \pm 0.8$ & $45.2 \pm 1.5$ \\
\hline \multicolumn{4}{|l|}{ Chemical analysis } \\
\hline $\mathrm{NE}_{\mathrm{L}}(\mathrm{Mcal} / \mathrm{kg})$ & 1.24 & 1.47 & 1.65 \\
\hline $\mathrm{CP}(\%$ of $\mathrm{DM})$ & 14.6 & 15.6 & 16.3 \\
\hline $\mathrm{ADF}(\%$ of $\mathrm{DM})$ & 36.2 & 30.2 & 24.1 \\
\hline $\mathrm{NDF}(\%$ of DM) & 52.7 & 44.7 & 37.9 \\
\hline
\end{tabular}

${ }^{1}$ The control diet (CON) was fed to all cows during the far-off dry period $(-50$ to $-21 \mathrm{~d}$ relative to expected calving); OVE $=$ overfeeding of a moderate-energy diet.

${ }^{2}$ SoyPLUS (West Central Soy, Ralston, IA).

${ }^{3}$ SoyChlor (West Central Soy).

${ }^{4}$ Energy Booster 100 (MSC, Carpentersville, IL).

${ }^{5}$ Contained a minimum of $5 \% \mathrm{Mg}, 10 \% \mathrm{~S}, 7.5 \% \mathrm{~K}, 2.0 \% \mathrm{Fe}, 3.0 \% \mathrm{Zn}$, $3.0 \% \mathrm{Mn}, 5,000 \mathrm{mg}$ of $\mathrm{Cu} / \mathrm{kg}, 250 \mathrm{mg}$ of I/ kg, $40 \mathrm{mg}$ of Co/kg, $150 \mathrm{mg}$ of Se/kg, 2,200 kIU of vitamin $\mathrm{A} / \mathrm{kg}, 660 \mathrm{kIU}$ of vitamin $\mathrm{D}_{3} / \mathrm{kg}$, and $7,700 \mathrm{IU}$ of vitamin $\mathrm{E} / \mathrm{kg}$.

${ }^{6}$ Contained 30,000 kIU/kg.

${ }^{7}$ Contained 5,009 kIU $/ \mathrm{kg}$.

${ }^{8}$ Contained 44,000 IU $/ \mathrm{kg}$.

${ }^{9}$ Means $\pm \mathrm{SD}$.

tion (IRS1-pY) were analyzed with a PathScan Total IRS-1 Sandwich ELISA kit (catalog \#7328; Cell Signaling Technology Inc.) and PathScan Phospho-IRS-1(pan Tyr) Sandwich ELISA kit (catalog \#7133; Cell Signaling Technology Inc.) according to the manufacturer's instructions. The phosphorylation level of IRS-1 was calculated by dividing absorbance values of IRS1-pY at $450 \mathrm{~nm}$ by absorbance values of total IRS-1 at $450 \mathrm{~nm}$. 


\section{RNA Extraction, Primer Design and Evaluation, Internal Control Gene Selection, and Real-Time Quantitative PCR}

Complete details are presented in the Supplemental Materials (available online at http://www.journalofdairyscience.org/). Briefly, we evaluated 8 candidate internal control genes (ICG) using GeNorm software (Vandesompele et al., 2002). Analysis revealed that genes encoding $\beta$ actin $(\boldsymbol{A C T \boldsymbol { B }})$, ribosomal protein $\mathrm{S} 9$ $(\boldsymbol{R P S 9})$ and glyceraldehyde-3-phosphate dehydrogenase $(\boldsymbol{G A P D H})$ were the most stably expressed and were used as ICG. Target genes were normalized with the geometric mean of the 3 ICG. Relative mRNA abundance was calculated for each gene among all of the genes tested in this study to provide additional mechanistic information on the target genes (Bionaz and Loor, 2008).

\section{Statistical Analysis}

To avoid problems with fitting covariance structure (Janovick and Drackley, 2010; Janovick et al., 2011), pre- and postpartal data for $\mathrm{DMI}, \mathrm{NE}_{\mathrm{L}}$ intake, energy balance, serum concentrations of insulin, BHBA, and NEFA were analyzed separately as a completely randomized design using the MIXED procedure of SAS (version 9.1; SAS Institute Inc., Cary, NC). The fixed effects in the model were close-up treatment (Trt), day or week, and Trt $\times$ time $(\operatorname{Trt} \times \mathrm{d}$ or Trt $\times$ wk $)$ for each variable analyzed. The REPEATED statement was used for variables measured over time (DMI, $\mathrm{NE}_{\mathrm{L}}$ intake, energy balance, milk yield, milk components, and serum insulin, BHBA, and NEFA). Autoregressive covariance structure was the best fit for these data as determined by the lowest Akaike's information criterion.

Phosphorylation of IRS1-PY from the negative control samples was analyzed as a $2 \times 2$ factorial arrangement in a completely randomized design using the MIXED procedure of SAS to evaluate the effects of close-up diets (Trt) and day relative to parturition. Cow within treatment and day was used as the random effect. The data for IRS1-PY from samples after insulin challenge were analyzed in a split-plot completely randomized design with the same SAS program to evaluate the main effects of Trt, day, and insulin challenge time (time) and all interactions. The estimate statement was used to analyze the difference of IRS1-PY between the negative control sample ( $0 \mathrm{~min}$, before insulin challenge) and insulin-challenged samples (15, 30, and 60 min). Cow within treatment and day was designated a random effect. The relative mRNA abundance data of the tested genes were normalized with the geometric mean of 3 ICG. To ensure normal distribution of residuals, the ICG-normalized data were subjected to square root transformation. This final data set was analyzed as a 2 (Trt) $\times 3$ (day) factorial arrangement in a completely randomized design, with day as a repeated measure using a PROC MIXED model. Contrasts were conducted for genes with significant interactions. Gene expression raw $P$-values were adjusted for multiple testing comparisons using false discovery rate (FDR) in SAS. Significant difference was declared at $P<0.05$ and tendency at $P<0.1$, and for gene expression at an FDR-adjusted $P \leq 0.05$ (raw $P \leq 0.02$ ).

\section{RESULTS}

\section{Performance, Serum Insulin and Metabolites, and Hepatic Lipid Accumulation}

Compared with CON, OVE cows had greater DMI $(P=0.05), \mathrm{NE}_{\mathrm{L}}$ intake $(P<0.01)$, energy balance $(P$ $<0.01)$, BCS $(P=0.01)$, and serum insulin concentration $(P<0.01)$ during the close-up period and tended $(P=0.06)$ to have greater circulating concentration of BHBA postcalving (Table 2). When comparing changes of serum NEFA from close-up to postpartum within each group, energy overfeeding resulted in greater $(P$ $=0.04)$ NEFA increase postcalving (Table 2; Supplemental Figures 1-4, available online at http://www. journalofdairyscience.org/). That response corresponded with the more drastic decrease in energy balance experienced by OVE cows (Table 2).

No difference in milk performance was observed between the 2 groups except for a tendency $(P=0.10)$ for lower milk protein percentage in OVE cows (Table 2; Supplemental Figure 2, available online at http:// www.journalofdairyscience.org/). Although postpartal compared with prepartal hepatic total lipid and triglyceride (TAG) concentration was greater in both groups, OVE cows had a more pronounced increase in both indices (Figure 1). Despite the greater liver TAG content, only 2 of the cows in the OVE group were classified as ketotic and 1 of those maintained normal intake relative to the entire group. Per farm protocols, these cows received oral propylene glycol and returned to normal within $5 \mathrm{~d}$ of treatment (i.e., before 14 DIM).

\section{IRS-1 Tyrosine Phosphorylation}

In the absence of the insulin challenge in vitro, the close-up dietary energy plane did not affect $(P>0.10)$ IRS1 phosphorylation at -10 or $7 \mathrm{~d}$ (Figure 2). Supraphysiological bovine insulin challenge significantly 
Table 2. Effect of close-up energy overfeeding $(\mathrm{OVE}, \mathrm{n}=7)$ or feeding to meet energy requirements $(\mathrm{CON}, \mathrm{n}=7)$ on $\mathrm{DMI}, \mathrm{NE} \mathrm{L}_{\mathrm{L}}$ intake, blood metabolites, and production of dairy cows (all data are presented as means $\pm \mathrm{SEM}$ )

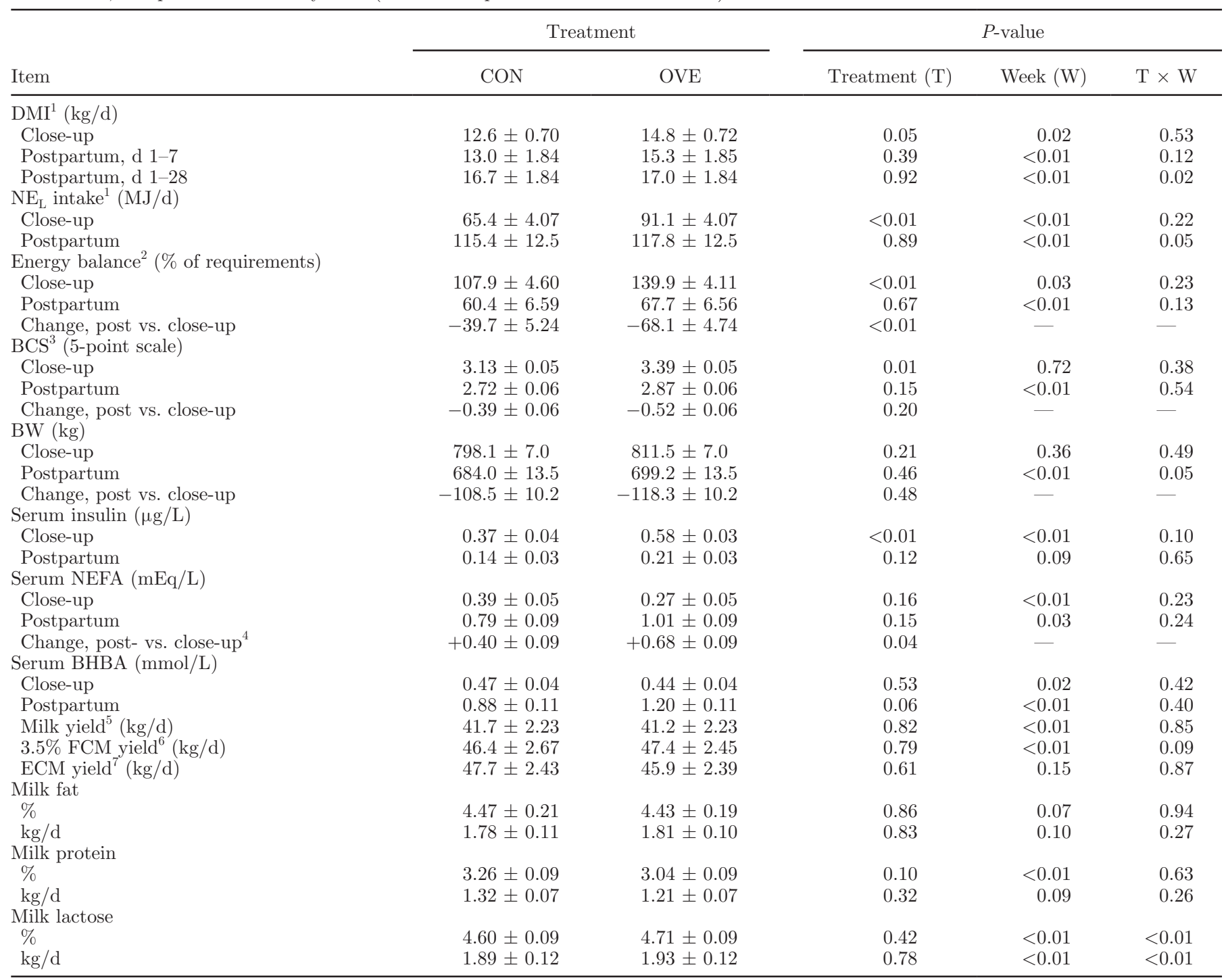

${ }^{1} \mathrm{DMI}$ and $\mathrm{NE}_{\mathrm{L}}$ intake were analyzed based on daily data from 1 to $28 \mathrm{~d}$.

${ }^{2}$ The energy balance of each animal was calculated weekly for data from -3 to 4 wk relative to parturition.

${ }^{3}$ The BCS of each animal at -4 wk was used as the covariate for both close-up and postpartum data. The postpartum BCS consists of data at 1 to $3 \mathrm{wk}$. Estimate statement was used to compare the effect of close-up dietary energy planes on serum NEFA change of postpartum vs. close-up period.

${ }^{4}$ Estimate statement was used to compare the effect of close-up dietary energy planes on serum NEFA change of postpartum vs. close-up period. Data set is composed of serum NEFA concentrations at $-14,-8$, and $-3 \mathrm{~d}$ for close-up period and $2,8,14$, and $21 \mathrm{~d}$ postpartum of each animal with 7 cows per treatment.

${ }^{5}$ Milk yield was analyzed based on daily data from 1 to $30 \mathrm{~d}$.

${ }^{6}$ Fat-corrected milk $=0.4324 \times($ milk yield $)+16.2162 \times($ fat yield $)$. Milk samples from the first week were not used to calculate FCM.

${ }^{7}$ Energy-corrected milk $=(0.327 \times$ milk yield $)+(12.95 \times$ fat yield $)+(7.2 \times$ protein yield $)$.

increased IRS1-PY in tissue from $-10(P<0.001)$ and $7 \mathrm{~d}(P<0.001$; caption of Figure 2). Lower $(P=0.05)$ IRS1-PY was observed for both groups at 7 compared with $-10 \mathrm{~d}$. The same pattern across time points (day,
$P=0.02)$ was observed for IRS1-PY in tissues challenged with insulin, although values of IRS1-PY were increased to a greater magnitude in response to insulin (Figure 2). 

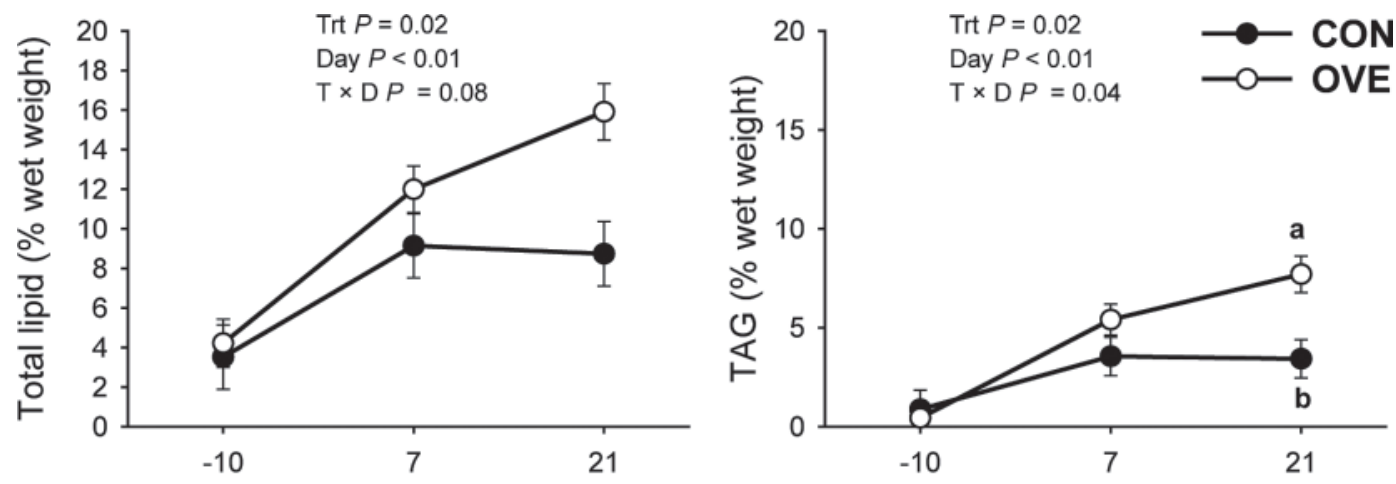

Day relative to parturition

Figure 1. Liver triacylglycerol (TAG) and total lipid content (\% of wet tissue) at $-10,7$, and $21 \mathrm{~d}$ relative to parturition in cows overfed a moderate-energy diet $(\mathrm{OVE}, \mathrm{n}=7)$ or fed to meet energy requirements $(\mathrm{CON}, \mathrm{n}=7)$ during the close-up period. Values are expressed as mean \pm SEM. The $P$-values for main effect of treatment $($ Trt) and day and interaction of treatment by day $(\mathrm{T} \times \mathrm{D})$ are shown. A contrast statement was used for mean separation within treatments when the interaction was significant $(P<0.05)$ at the same day relative to parturition. In those instances, significant differences $(P<0.05)$ are denoted with lowercase a and $\mathrm{b}$.

\section{Gene Expression}

Expression of the preadipocyte marker delta-like 1 homolog (DLK1, or PREF1) was only detectable in approximately $30 \%$ of samples at -10 and $7 \mathrm{~d}$ (data not shown), whereas expression of the triacylglycerol lipase adiponutrin ( $A D P N$ or $P N P L A 3)$ and fibroblast growth factor 21 (FGF21) was undetectable in most samples. Thus, data for these genes were not analyzed statistically.

Insulin Signaling Pathway. As shown in Figure 3, no treatment or interaction effect (FDR-adjusted $P=$ 0.10) was detected for insulin receptor (INSR) mRNA expression and other components of postreceptor signaling v-akt murine thymoma viral oncogene homolog
1 (AKT1 and AKT2). Expression of AKT2 decreased overall after calving (day $P=0.001$ ). Overfeeding compared with CON resulted in greater overall $(P \leq$ 0.05) 3-phosphoinositide dependent protein kinase-1 $(P D P K 1)$ and sterol regulatory element-binding protein cleavage-activating protein $(\boldsymbol{S C A P})$ and a tendency $(P=0.13)$ of greater overall IRS1 expression due to the response at -10 and $7 \mathrm{~d}$ for PDPK1 and SCAP, and at $21 \mathrm{~d}$ postcalving for IRS1. In fact, expression of IRS1 mRNA exhibited the greatest response among these set of genes because it increased $(P<0.001)$ markedly ( $>3$ fold) due to OVE at 21 compared with 7 d. Despite the greater expression of $S C A P$, a coactivator of sterol regulatory element binding transcription factor 1 (SREBF1; Foufelle and Ferré, 2002), the

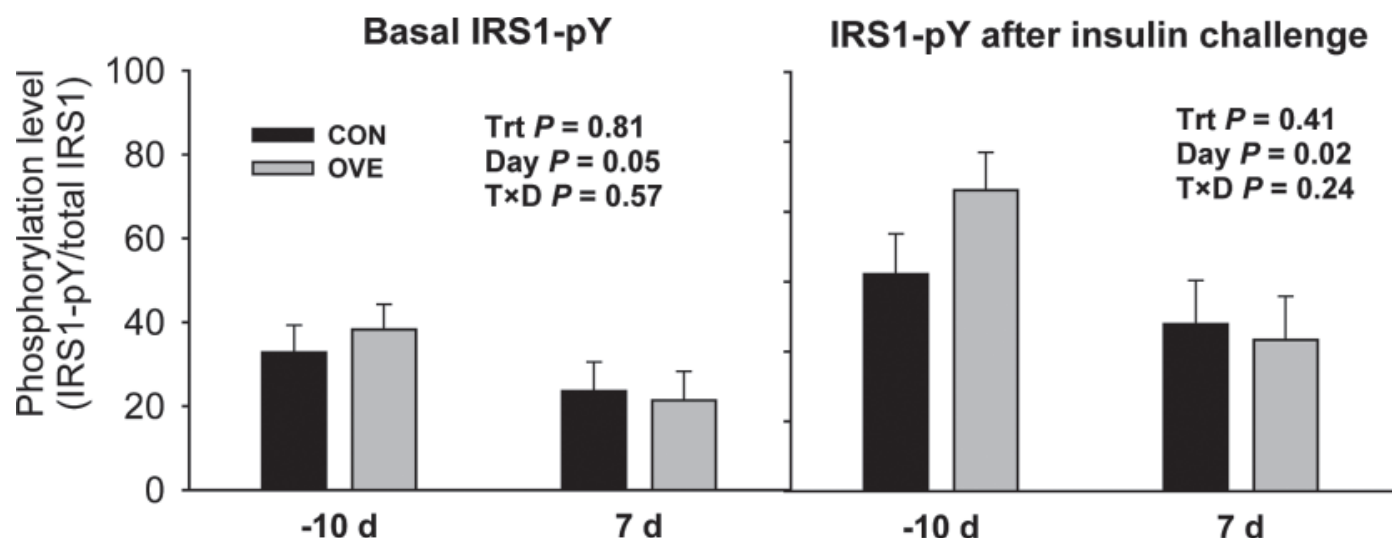

Figure 2. In vitro basal or insulin-stimulated insulin receptor substrate 1 (IRS-1) tyrosine phosphorylation (IRS1-PY) level in adipose tissue (AT) from cows overfed a moderate-energy diet $(\mathrm{OVE}, \mathrm{n}=7)$ or fed to meet energy requirements $(\mathrm{CON}, \mathrm{n}=6)$ during the close-up period. Values are expressed as mean \pm SEM. The difference of IRS1-PY between negative control samples and insulin-challenged samples was $-39.2 \%$ at $-10 \mathrm{~d}(P<0.001)$ and $-23.1 \%$ at $7 \mathrm{~d}(P<0.001)$. 
expression of the well-established insulin-induced lipogenic transcription regulator $S R E B F 1$ was lower (Trt $\times$ day, $P=0.02$ ) for OVE at $-10 \mathrm{~d}$; cows fed CON experienced a decrease in $S R E B F 1$ expression between -10 and $7 \mathrm{~d}$ and even though expression increased by $21 \mathrm{~d}$, it remained lower than at $-10 \mathrm{~d}$. The expression of eukaryotic translation initiation factor 4E-binding protein 1 (EIF4EBP1) and phosphodiesterase 3B $(\boldsymbol{P D E} \boldsymbol{B})$ between -10 and $7 \mathrm{~d}$ increased (day, $P<$ 0.001 ); however, expression of both genes was greater overall (Trt, $P \leq 0.05$ ) in response to feeding CON, which was primarily due to levels observed at -10 and 7 d (Figure 3).

Cows fed OVE had greater mRNA expression of the insulin-induced glucose transporter 4 ( GL UT4) at -10 $\mathrm{d}(P<0.05)$, but the expression was sharply downregulated $(P<0.05)$ postpartum in both groups. A Trt $\times$ day interaction $(P<0.05)$ was observed for the expression of the facilitated glucose transporter GLUT1 due to an increase between 7 and $21 \mathrm{~d}$, at which point expression was greater in cows fed CON (Figure 3). It should be noted, however, that the relative mRNA abundance of GLUT4 was substantially greater than GLUT1, underscoring the key role of GLUT4 in AT glucose uptake (Supplemental Table 1, available online at http://www.journalofdairyscience.org/).

Adipogenesis and Lipogenesis Control. As shown in Figure 4, a significant $(P<0.05)$ main effect of prepartal plane of dietary energy was detected for mRNA expression of the major adipogenic transcription regulator peroxisome proliferator-activated receptor $\gamma$ (PPARG; Rosen and MacDougald, 2006), whereas expression of CCAAT/enhancer-binding protein $\alpha$ ( $\boldsymbol{C E B P A})$ tended $(P=0.08)$ to differ. The main effect was primarily due to feeding OVE compared with CON leading to a remarkably greater $(P<0.05)$ expression of PPARG at both -10 and $7 \mathrm{~d}$ (Figure 4). Similar responses were observed for insulin induced gene 1 (INSIG1) and INSIG2, 2 key players in preadipocyte differentiation (Rosen and MacDougald, 2006), namely due to greater $(P<0.02)$ expression at $-10 \mathrm{~d}$ in response to OVE. The PPAR $\gamma$-regulated adipokine adiponectin $(\boldsymbol{A D I P O Q})$ tended $(P=0.07)$ to be greater overall due to feeding OVE, namely due to responses at -10 and $7 \mathrm{~d}$. Despite the fact that angiopoietin-related protein 4 (ANGPTL4) has been recently recognized as a PPAR $\gamma$ target in mice AT (Dutton and Trayhurn, 2008), its expression was lower (Trt $\times$ day, $P=0.01$ ) at -10 in cows fed OVE compared with those fed CON. Marked upregulation of ANGPTL4 occurred between -10 and $7 \mathrm{~d}$, regardless of treatment; however, by $\mathrm{d}$ 21 expression remained high in cows fed CON but decreased in cows fed OVE leading to lower (Trt $\times$ day, $P=0.01)$ expression.
Despite what appeared to be a robust proadipogenic response around parturition, the expression of the recently-discovered PPAR $\gamma$ regulator zinc finger protein 423 (ZFP423; Gupta et al., 2010) did not differ due to treatment $(P=0.98)$ or $\operatorname{Trt} \times$ day $(P=0.54)$ but its expression increased (day $P<0.001$ ) 2 fold between -10 through $21 \mathrm{~d}$ (Figure 4). Furthermore, the expression of the PPAR $\gamma$ coactivator lipin-1 (LPIN1) did not differ prepartum but increased (Trt $\times$ day, $P$ $=0.01)$ ca. 2 fold between -10 and $7 \mathrm{~d}$ in cows fed OVE compared with CON, followed by a decrease to prepartal levels by $21 \mathrm{~d}$ (Figure 4 ).

FA Uptake, de novo Lipogenesis, and Desaturation. In agreement with the robust proadipogenic response observed prepartum, close-up energy overfeeding resulted in a coordinated upregulation (Trt $x$ day, $P \leq 0.03$ ) of genes involved in FA uptake and activation [lipoprotein lipase $(\boldsymbol{L P L})$, acyl-CoA synthetase short-chain family member 2 (ACSS2), acyl-CoA synthetase long-chain family member 1 (A $\boldsymbol{C S L 1})]$, de novo FA synthesis and desaturation [ATP citrate lyase $(\boldsymbol{A} \boldsymbol{C L} \boldsymbol{Y})$, acetyl-CoA carboxylase $\alpha(\boldsymbol{A} \boldsymbol{C A} \boldsymbol{C A}), \mathrm{FA}$ synthase $(\boldsymbol{F A} \boldsymbol{S} \boldsymbol{N})$, lactate dehydrogenase B $(\boldsymbol{L} \boldsymbol{D} \boldsymbol{H} \boldsymbol{B})$, stearoyl-CoA desaturase $(S C D)]$, NADPH production and glyceroneogenesis [glucose-6-phosphate dehydrogenase $(G 6 P D)$, isocitrate dehydrogenase 1 (IDH1), and phosphoenolpyruvate carboxykinase 1 (PCK1)], and TAG synthesis [glycerol-3-phosphate acyltransferase 1, mitochondrial ( $\boldsymbol{G P A} \boldsymbol{M}$ ), diacylglycerol $O$-acyltransferase 2 (DGAT2)] at $-10 \mathrm{~d}$ (Figure 5). The overall day effect $(P<0.001)$ observed for the expression of these genes clearly was due to the marked decrease in expression in cows fed OVE between -10 and $7 \mathrm{~d}$, after which expression remained unchanged (except for $L D H B$ ). In cows fed CON, few genes (e.g., FASN, ACSS2, GPAM, and DGAT2) had a marked change in expression at -10 vs. 7 and 21 d. Expression of solute carrier family 27 (FA transporter), member 1 (SLC27A1), cluster of differentiation 36 (CD36), FA-binding protein 4 $(\boldsymbol{F A B P} 4)$, and 1-acylglycerol-3-phosphate $O$-acyltransferase 6 (AGPAT6) increased, regardless of treatment (day, $P<0.02$ ) by $21 \mathrm{~d}$ (Figure 5).

Lipolysis Control. Prepartal energy overfeeding led to greater (Trt $\times$ day, $P<0.05)$ mRNA expression at $-10 \mathrm{~d}$ of the regulatory enzyme controlling basal lipolysis adipose triglyceride lipase $(\boldsymbol{A T G L})$, and despite a decrease in expression by $7 \mathrm{~d}$, cows fed OVE still had greater $A T G L$ expression at that point relative to CON (Figure 6). That pattern of expression was accompanied by a greater overall (Trt $P<$ 0.03) expression of the coactivator abhydrolase domain containing 5 (ABHD5). Similar to ATGL, expression of monoglyceride lipase $(\boldsymbol{M G} \boldsymbol{L} \boldsymbol{L})$ was greater $($ Trt $\times$ day, $P<0.05)$ at $-10 \mathrm{~d}$ and then decreased by $7 \mathrm{~d}$, 

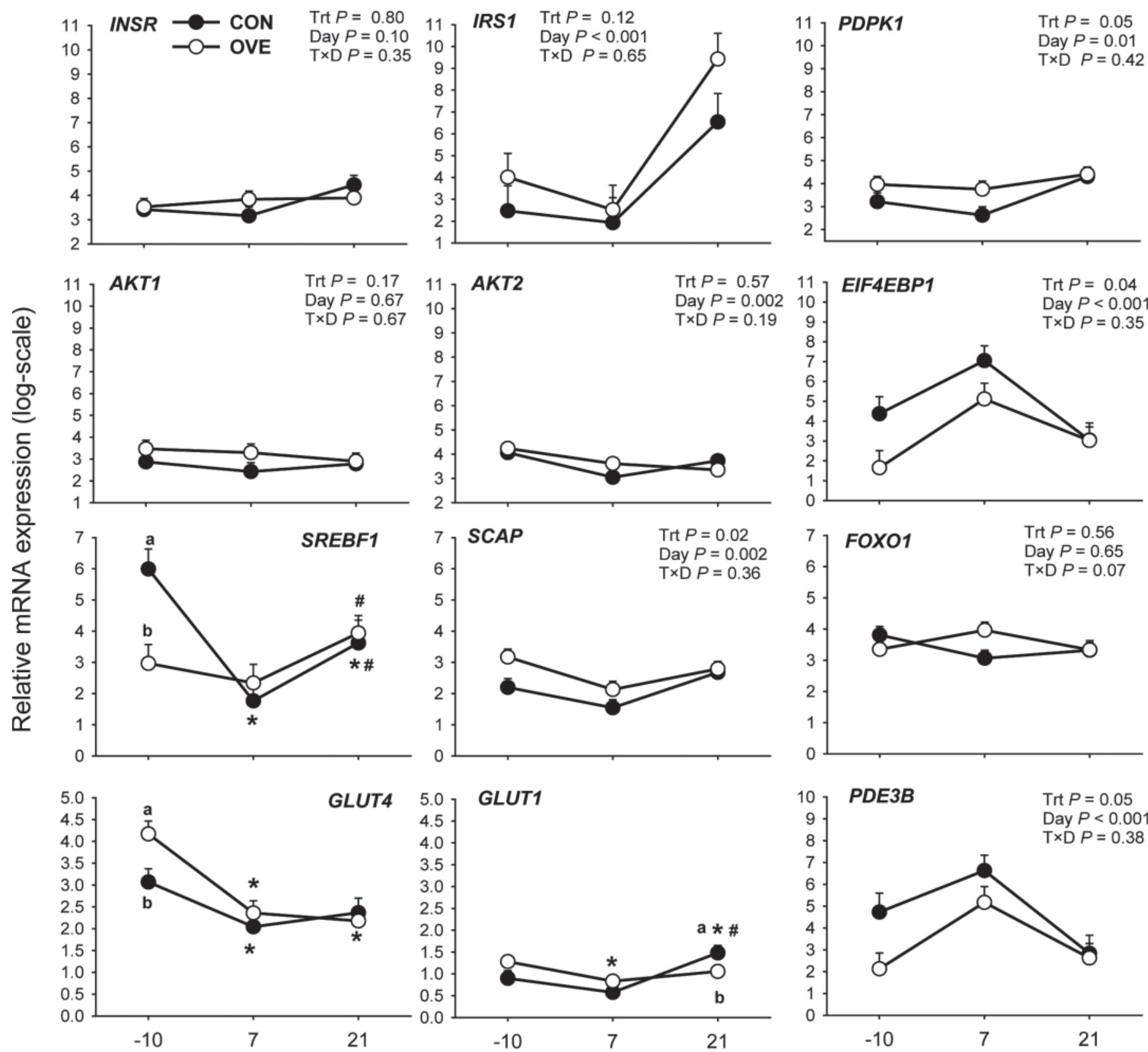

Day relative to parturition

Figure 3. Expression of genes involved in insulin binding [insulin receptor (INSR)] and postreceptor signaling [insulin receptor substrate 1 (IRS1), 3-phosphoinositide dependent protein kinase-1 (PDPK1), v-akt murine thymoma viral oncogene homolog 1 (AKT1), AKT2, phosphodiesterase 3B (PDE3B), eukaryotic translation initiation factor 4E-binding protein 1 (EIF 4EBP1)], insulin-regulated transcriptional control of lipogenesis [sterol regulatory element-binding protein cleavage-activating protein $(S C A P)$ and sterol regulatory element binding transcription factor 1 (SREBF1)], and glucose transport [insulin-induced glucose transporter 1 (GLUT1) and GLUT4] in subcutaneous adipose tissue of cows overfed a moderate-energy diet $(\mathrm{OVE}, \mathrm{n}=7$ ) or fed to meet energy requirements $(\mathrm{CON}, \mathrm{n}=7)$ during the close-up period. Values are expressed as mean \pm SEM. The false discovery rate-adjusted $P$-values for main effect of treatment (Trt) and day and interaction of treatment $\times$ day $(\mathrm{T} \times$ $\mathrm{D})$ are shown only for those genes without significant interactions $(\mathrm{T} \times \mathrm{D})$. For genes with significant interaction $(P<0.05)$, mean separation was evaluated via contrasts at the same day relative to parturition and significant differences $(P<0.05)$ are denoted with lowercase a and b. Mean separation between time points and within treatments were evaluated via contrasts and significant differences $(P<0.05)$ between $\mathrm{d}-10$ and 7 or 21 are denoted with an asterisk (*), and between $\mathrm{d} 7$ and 21 by a pound sign (\#). 

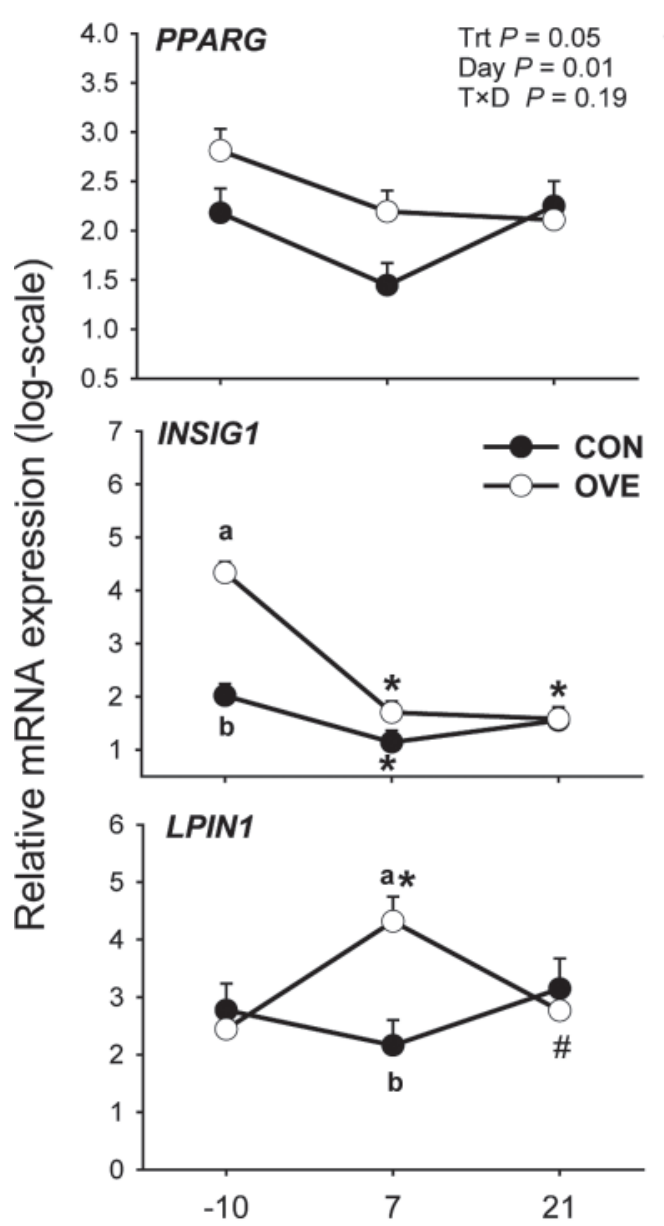
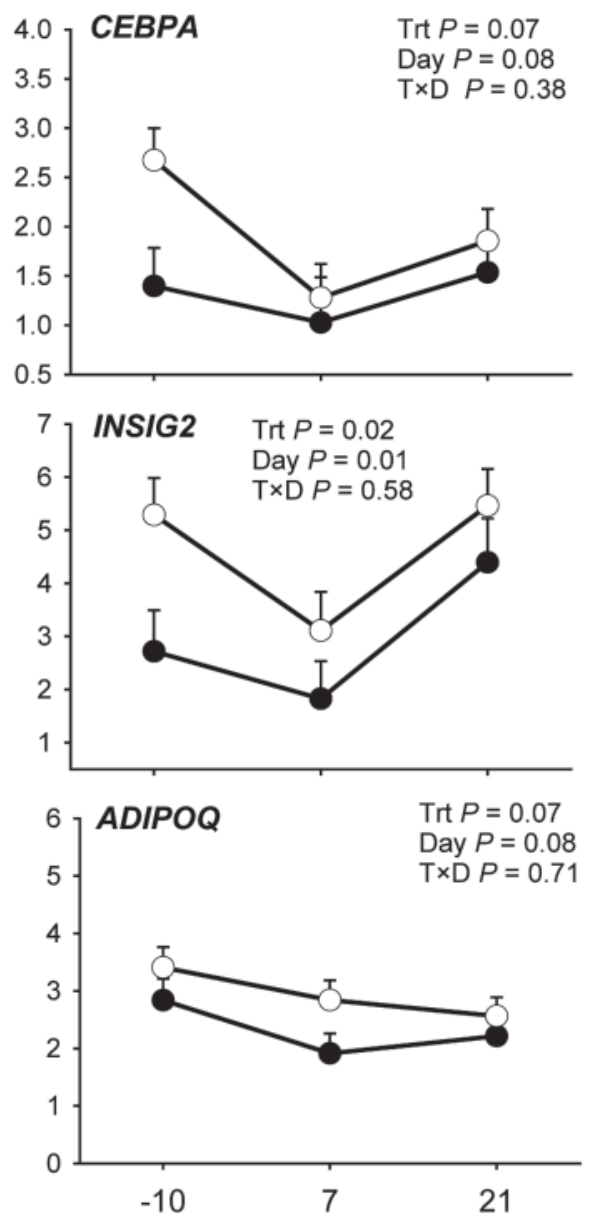

Day relative to parturition

Figure 4. Expression of adipogenic transcription regulators [proliferator-activated receptor $\gamma(P P A R G)$, CCAAT/enhancer-binding protein $\alpha(C E B P A)$, and zinc finger protein 423 (ZFP423)], PPAR $\gamma$-driven inducers of lipogenesis [insulin induced gene 1 (INSIG1) and INSIG2], PPAR $\gamma$ - and $\mathrm{CEBP} \alpha$-regulated adipokines [angiopoietin-related protein 4 (ANGPTL4) and adiponectin $(A D I P O Q)$ ], and lipogenic transcription regulator lipin-1 (LPIN1) in subcutaneous adipose tissue of cows overfed a moderate-energy diet (OVE, $\mathrm{n}=7)$ or fed to meet energy requirements $(\mathrm{CON}, \mathrm{n}=7$ ) during the close-up period. Values are expressed as mean \pm SEM. The false discovery rate-adjusted $P$-values for main effect of treatment (Trt) and day and interaction of treatment $\times$ day $(\mathrm{T} \times \mathrm{D})$ are shown only for those genes without significant interactions $(\mathrm{T} \times \mathrm{D})$. For genes with significant interaction $(P<0.05)$, mean separation was evaluated via contrasts at the same day relative to parturition and significant differences $(P<0.05)$ are denoted with lowercase a and $\mathrm{b}$. Mean separation between time points and within treatments were evaluated via contrasts and significant differences $(P<0.05)$ between $\mathrm{d}-10$ and 7 or 21 are denoted with an asterisk $(*)$, and between $\mathrm{d} 7$ and d 21 by a pound sign (\#).

after which it remained unchanged in cow fed OVE but increased ca. 3 fold in cows fed CON. The mRNA expression of hormone-sensitive lipase $(\boldsymbol{H S L})$ in SAT was relatively more stable around parturition between treatments, despite a tendency $(P=0.10)$ for a day effect, which was mainly due to the lower expression in CON at $7 \mathrm{~d}$ (Figure 6).

Although expression of the lipid droplet-associated protein perilipin 1 (PLIN1) was not affected, expression of PLIN2 (the most-abundant in AT lipid droplets; Duncan et al., 2007) was greater overall $(P=0.01)$ in cows fed OVE compared with CON due to responses at
-10 and $7 \mathrm{~d}$. The mRNA expression of growth hormone receptor $(\boldsymbol{G H R})$ was greater $(P=0.05)$ overall in cows fed OVE vs. CON primarily due to the response at -10 and $7 \mathrm{~d}$. In fact, the pattern of expression of $A T G L$, $A B H D 5$, and PLIN2 at -10 and $7 \mathrm{~d}$ was strikingly similar to that of $G H R$.

The mRNA expression of $\beta-2$ adrenergic receptor (ADRB2), encoding the major $\beta$-adrenergic receptor in adipocytes, and the glucocorticoid receptor nuclear receptor subfamily 3 , group $\mathrm{C}$, member 1 (NR3C1) increased $(P \leq 0.001)$ at $21 \mathrm{~d}$ compared with $-10 \mathrm{~d}$ regardless of treatment (Figure 6). The ADRB1 mRNA 

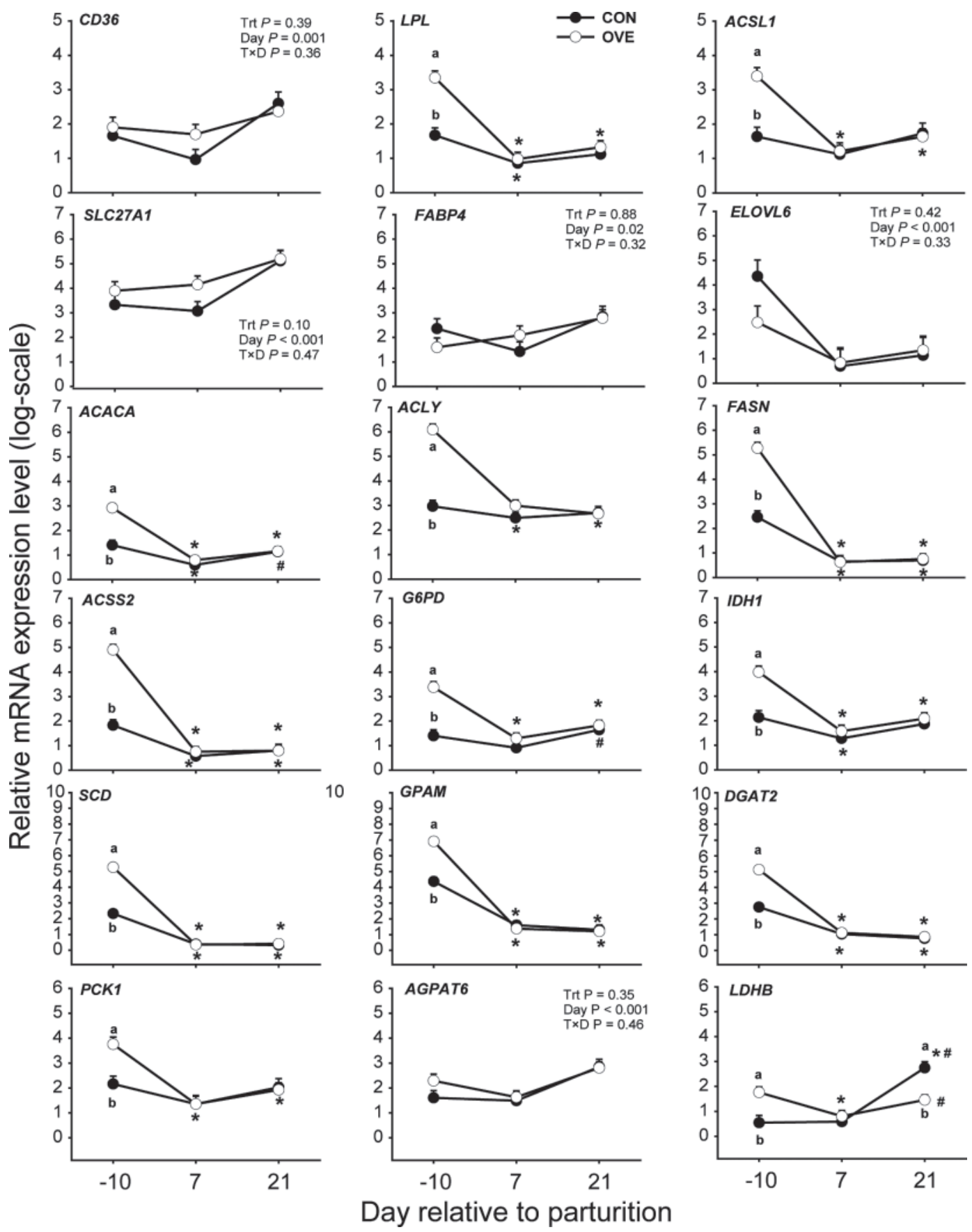

Figure 5. Expression of genes encoding enzymes associated with long-chain FA (LCFA) import and activation [cluster of differentiation 36 (CD36); solute carrier family 27 (FA transporter), member 1 (SLC27A1); lipoprotein lipase (LPL); FA-binding protein 4 (FABP4); and acylCoA synthetase long-chain family member $1(A C S L 1)$, de novo FA synthesis [ATP citrate lyase $(A C L Y)$, acetyl-CoA carboxylase $\alpha(A C A C A)$, FA synthase $(F A S N)$, and lactate dehydrogenase B $(L D H B)$ ], desaturation and elongation [stearoyl-CoA desaturase $(S C D)$ and FA elongase 6 (ELOVL6)], cytosolic acetate activation [acyl-CoA synthetase short-chain family member 2 (ACSS2)], cytosolic NADPH production [glucose6-phosphate dehydrogenase $(G 6 P D)$ and isocitrate dehydrogenase 1 (IDH1)], triglyceride (TAG) synthesis [glycerol-3-phosphate acyltransferase 1, mitochondrial $(G P A M)$; 1-acylglycerol-3-phosphate $O$-acyltransferase 6 (AGPAT6); and diacylglycerol $O$-acyltransferase 2 (DGAT2)], and glyceroneogenesis [phosphoenolpyruvate carboxykinase $1(P C K 1)$ ] in subcutaneous adipose tissue of cows overfed a moderate-energy diet (OVE, $\mathrm{n}=7$ ) or fed to meet energy requirements $(\mathrm{CON}, \mathrm{n}=7)$ during the close-up period. Values are expressed as mean \pm SEM. The false discovery rate-adjusted $P$-values for main effect of treatment $($ Trt $)$ and day and interaction of treatment $\times$ day $(\mathrm{T} \times \mathrm{D})$ are shown only for those genes without significant interactions $(\mathrm{T} \times \mathrm{D})$. For genes with significant interaction $(P<0.05)$, mean separation was evaluated via contrasts at the same day relative to parturition and significant differences $(P<0.05)$ are denoted with lowercase a and b. Mean separation between time points and within treatments were evaluated via contrasts and significant differences $(P<0.05)$ between $\mathrm{d}-10$ and 7 or 21 are denoted with an asterisk $(*)$, and between $\mathrm{d} 7$ and 21 by a pound sign (\#). 

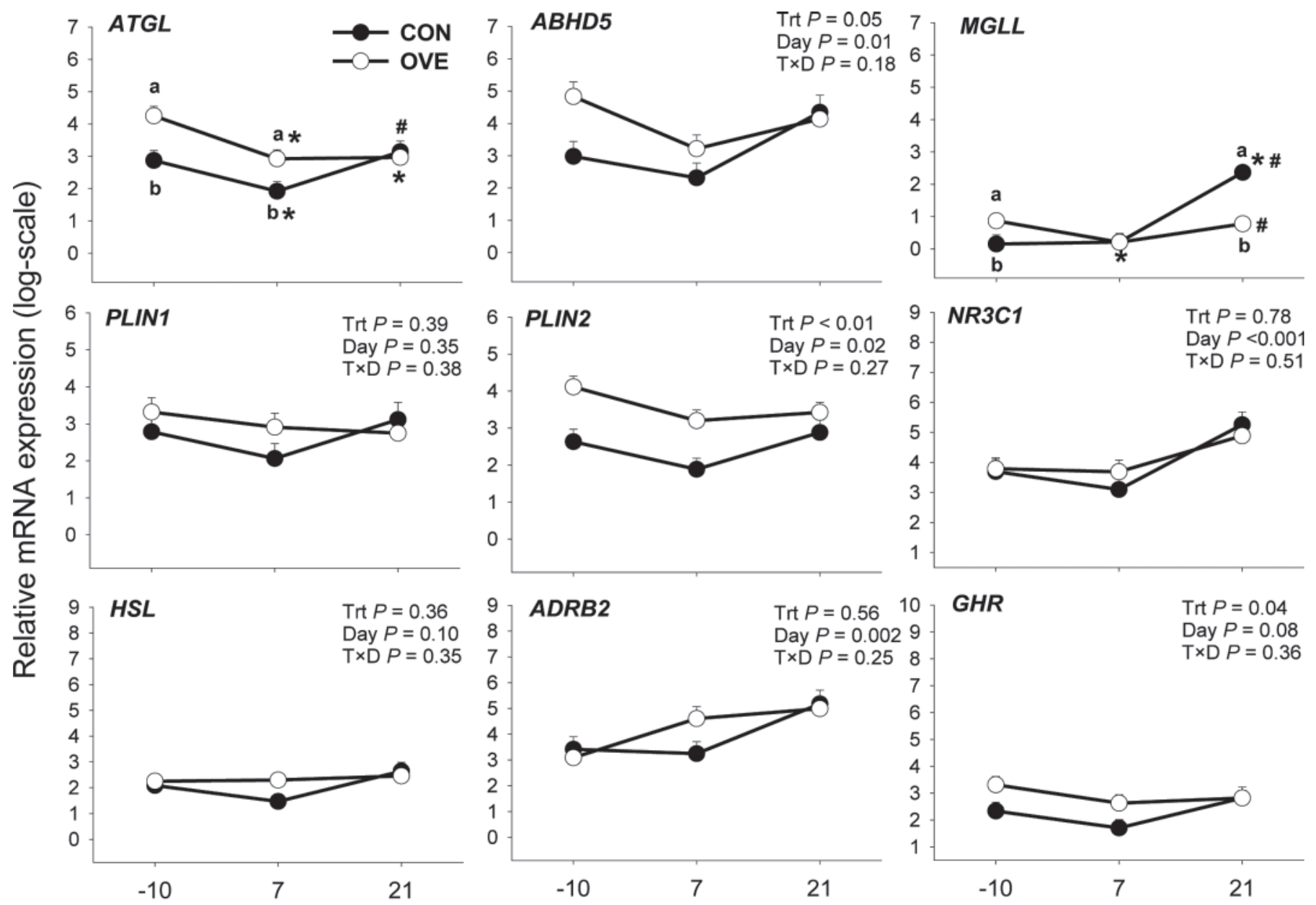

Day relative to parturition

Figure 6. Expression of lipolytic enzymes [adipose triglyceride lipase $(A T G L)$, abhydrolase domain containing $5(A B H D 5)$, hormone-sensitive lipase $(H S L)$, and monoglyceride lipase $(M G L L)$ ], lipolytic inducers [growth hormone receptor $(G H R)$; nuclear receptor subfamily 3 , group C, member 1 (NR3C1); and $\beta-2$ adrenergic receptor (ADRB2)], and lipid droplet-associated proteins [perilipin 1 (PLIN1) and PLIN2] in subcutaneous adipose tissue of cows overfed a moderate-energy diet (OVE, $\mathrm{n}=7$ ) or fed to meet energy requirements $(\mathrm{CON}, \mathrm{n}=7)$ during the close-up period. Values are expressed as mean \pm SEM. The false discovery rate-adjusted $P$-values for main effect of treatment (Trt) and day and interaction of treatment $\times$ day $(\mathrm{T} \times \mathrm{D})$ are shown only for those genes without significant interactions $(\mathrm{T} \times \mathrm{D})$. For genes with significant interaction $(P<0.05)$, mean separation was evaluated via contrasts at the same day relative to parturition and significant differences $(P<0.05)$ are denoted with lowercase a and $\mathrm{b}$. Mean separation between time points and within treatments were evaluated via contrasts and significant differences $(P$ $<0.05$ ) between $\mathrm{d}-10$ and 7 or 21 are denoted with an asterisk $(*)$, and between $\mathrm{d} 7$ and 21 by a pound sign (\#).

abundance was ca. one-hundredth the level of $A D R B 2$ (Supplemental Table 1, available online at http://www. journalofdairyscience.org/), and ADRB3 was undetectable in most AT samples (data not shown).

\section{DISCUSSION}

\section{Production Responses}

Similar to our previous studies (e.g., Richards et al., 2009; Janovick and Drackley, 2010), CON successfully controlled the DMI during the entire dry period and limited $\mathrm{NE}_{\mathrm{L}}$ intake close to predicted requirements. Limitation of DMI was due to the bulky nature of wheat straw and the ensuing rumen-fill response. The greater prepartal concentration of insulin in response to energy overfeeding in the present and previous studies (Holtenius et al., 2003; Dann et al., 2006; Janovick et al., 2011) might have been due to 1) greater ground shelled corn consumption, resulting in greater hepatic gluconeogenesis, which subsequently stimulated pancreatic insulin secretion; or 2) the combination of greater gluconeogenesis-stimulated insulin production and exacerbated peripheral IR. Recently, Schoenberg 
et al. (2012) used a glucose tolerance test (GTT) and hyperinsulinemic-euglycemic clamp (HEC) to evaluate the insulin responsiveness of dry cows overfed or restricted fed dietary energy (162 or 90\% of requirements) for $14 \mathrm{~d}$. Similar to our study, they observed greater basal plasma insulin in overfed cows as well; however, no differences existed in glucose clearance rate or increased plasma insulin in response to GTT and HEC. As such, those data do not support a compromised IR state in overfed cows.

The same pre- and postpartal patterns in circulating NEFA between OVE and CON cows as in the current study have been observed in previous studies in which overfeeding was implemented for the entire dry period (Janovick et al., 2011; Khan et al., 2011) or only during the close-up period (Vasquez et al., 2011). Rukkwamsuk et al. (1998) reported that SAT biopsied at -1 wk relative to parturition from cows overfed compared with restricted fed energy during the entire dry period had lower basal lipolytic rate in vitro, but tended to have greater noradrenaline-stimulated lipolysis. A second study from the same group demonstrated that SAT from the same overfed cows had greater in vitro rates of basal esterification at -1 wk (Rukkwamsuk et al., 1999), which probably helped recycle mobilized NEFA into TAG (Nye et al., 2008). Both types of adaptations help explain the lower prepartal adipose lipolytic rate in overfed cows (i.e., lower NEFA; Janovick et al., 2011; Vasquez et al., 2011; Khan et al., 2011) and the greater increase in NEFA we observed postpartum compared with prepartum in cows fed OVE.

Despite the fact that postpartal DMI and energy balance did not differ between groups in the current study, OVE cows still experienced a more pronounced increase in serum NEFA, which indicated that a carryover effect of prepartal plane of energy nutrition affects the mechanisms controlling lipolysis, the sensitivity to lipolytic stimulation, or a combination of the 2 aspects. The discussion below expands on the putative molecular mechanisms responsible for these systemic responses.

\section{IRS-1 Tyrosine Phosphorylation and Insulin Signaling}

The underlying mechanisms of insulin signaling or IR during the transition period are still unclear. Using the hyperinsulinemic euglycemic clamp Petterson et al. (1993) demonstrated that IR during late pregnancy in sheep was primarily due to impaired peripheral insulin sensitivity, which suggested that the mechanisms involved reduction in INSR binding or dysfunction in early postreceptor signal transduction. Early studies regarding alterations of INSR numbers and binding affinity were mainly conducted with ewes and failed to give conclusive results (Vernon et al., 1981; Vernon and Taylor, 1988; Guesnet et al., 1991). Guesnet et al. (1991) reported a $62 \%$ decrease of INSR, accompanied by markedly decreased insulin-stimulated lipogenesis in omental AT of early lactating ewes. Vernon and Taylor (1988) showed that, compared with nonlactating controls, SAT from early lactation ewes had both reduced sensitivity and response to insulin-stimulated glucose uptake and FA synthesis in vitro. However, neither number nor binding affinity of INSR differed between the 2 physiological states. Recently, a similar study showed that the mRNA expression of INSR in SAT of peripartal dairy cows remained unchanged from $8 \mathrm{wk}$ pre- to 5 wk postpartum (Sadri et al., 2010). In the current study, with greater degree of variation, INSR expression was not affected during the transition period, which a priori highlighted a weak association with control of insulin signaling or IR during the transition period.

Vernon and Taylor (1988) attributed lactational IR to defects in intracellular insulin signaling transduction at the postreceptor level. At the molecular level, IRS proteins carry out the first intracellular step mediating insulin signaling. IRS-1, rather than the other isoforms, is preferentially involved in insulin-induced metabolic actions including glucose uptake (Saltiel and Kahn, 2001). Phosphorylation of IRS-1 on tyrosine residues is required for insulin-stimulated glucose uptake, and a substantial body of research demonstrated a causal relationship between compromised IRS1-PY and AT IR in both late pregnant rodents (Sevillano et al., 2007) and obesity-induced Type II diabetes (Esposito et al., 2001; Sesti et al., 2001). The level of IRS1-PY is relatively sustained even in the presence of phosphatases (Ogihara et al., 1997); thus, we assumed that the phosphorylation of IRS-1 in SAT adapted to culture medium without bovine insulin for 30 min was still representative of the basal physiological state (Figure 2 ). The lower level of IRS1-PY at 7 compared with -10 d postpartum suggested a decrease in insulin signaling after calving. However, we do not believe that this result alone was indicative of an exacerbated IR state in early lactation because lower IRS1-PY also may have been due to the postpartal hypoinsulinemia observed.

We expected that a supraphysiological challenge with bovine insulin would elicit a maximal response in IRS1-PY, which was clearly shown by the much higher phosphorylation level after insulin challenge (Figure 2), particularly in tissue harvested prepartum. Thus, as suggested previously (Bauman and Currie, 1980), cows seemed to experience a more severe peripheral IR early postpartum regardless of prepartal diet. The lack of 
change in INSR and IRS1 mRNA expression between -10 and $7 \mathrm{~d}$ suggested that during the short period of time around calving a defect in posttranslational modification of IRS1 likely was a major mechanism exacerbating IR. Such a mechanism is supported by the small change in expression observed for AKT2 and PDPK1, both of which are downstream targets of IRS and mediate intracellular insulin signaling transduction (Foufelle and Ferré, 2002).

The decrease in expression of GLUT4 by $7 \mathrm{~d}$ regardless of prepartal dietary energy is another piece of evidence supporting the diminished responsiveness of SAT to insulin during early lactation. Feed deprivation had been practiced to mimic the postcalving negative energy balance. During an HEC study, Schoenberg et al. (2012) observed a decrease in glucose disposal rate in dry cows deprived of feed for $2 \mathrm{~d}$ compared with ad libitum-fed controls. Decreased insulin responsiveness during feed deprivation has been reported in other studies as well (Oikawa and Oetzel, 2006). Whether compromised peripheral insulin responsiveness during acute feed deprivation resulted from decreased GLUT4 expression warrants further research.

Contrary to our hypothesis, prepartal data on insulinstimulated IRS1-PY and expression of GLUT4 mRNA (along with adipogenic and lipogenic genes) suggested that close-up energy overfeeding did not predispose animals to a state with greater IR. If anything, it seemed to have enhanced insulin sensitivity and responsiveness, particularly prepartum, and not to hamper it during the first $21 \mathrm{~d}$ postpartum. The data seem to confirm data from Holtenius et al. (2003) who reported a greater glucose clearance rate after a GTT at 3 wk before calving in overfed compared with underfed cows.

Insulin's antilipolytic effect is mediated by PDE3B, which hydrolyzes cAMP into AMP, and consequently reduces the magnitude of hormone-stimulated lipolysis in AT. The increase in PDE3B, regardless of diet between -10 and $7 \mathrm{~d}$ (Figure 3), might have served as a feedback-regulatory mechanism to prevent excessive lipolysis. We speculate that such a mechanism was activated due to either a blunted antilipolytic response by insulin (e.g., decrease in IRS1-PY postpartum) or increased lipolysis. Thus, it is not surprising that cows fed less energy (CON vs. OVE) had greater expression of $P D E 3 B$ at $-10 \mathrm{~d}$ to restrict further lipolysis. Despite an increase in both groups, the sustained higher expression of PDE3B in CON cows by $7 \mathrm{~d}$ may have contributed to the modest increase in plasma NEFA concentration postpartum, as evidenced in the current and previous studies (Dann et al., 2006; Janovick et al., 2011). Schoenberg et al. (2012) reported that feeddeprived or energy-restricted cows compared with ad libitum-fed or overfed controls were much more sensitive to an inhibition of lipolysis as assessed by a GTT. Those responses might have been at least partly regulated by greater expression of $P D E 3 B$.

Perhaps the most clear evidence of diminished insulin sensitivity due to change in physiological state was the 3-fold decrease in SREBF1 and also GLUT4 expression at $7 \mathrm{~d}$ in cows fed CON. Such a response of $S R E B F 1$ was not observed in cows fed OVE, perhaps due to the greater expression of its coactivator $S C A P$. At least in rodent liver, the expression and activity of SREBF1 is regulated primarily via insulin (Foufelle and Ferré, 2002). Our prepartal data do not seem to support an essentiality for SREBF1 as a regulator of SAT lipogenesis (Sekiya et al., 2007). The mechanistic role of $S R E B F 1$ in coordinating functional adaptations of bovine SAT deserves further study.

Insulin inhibits the expression of EIF $4 E B P 1$, a response that favors protein translation to proceed (Proud, 2002) and could explain the lower prepartal expression in cows fed OVE (i.e., those with greater blood insulin; Table 2). The sustained upregulation of $E I F 4 E B P 1$ soon after calving due to OVE was intriguing but supports the data from other genes examined (e.g., PPARG and CEBPA), providing evidence that insulin signaling (despite the reduction in IRS1-PY) was not impaired with OVE. Regardless of the diet, the observed increase in both EIF4EBP1 and ANGPTL4 expression by $7 \mathrm{~d}$ was similar to that observed in human SAT after an 8-wk period of low caloric intake in which fat mass and blood insulin decreased markedly (Franck et al., 2011). Thus, despite prepartal differences in blood insulin due to OVE as compared with CON, the temporal decrease in blood insulin with both treatments agrees with the increase in EIF4EBP1. Whether the EIF $4 E B P 1$ response represents another counterregulatory mechanism to control the overall process of translation in SAT as a way to conserve energy and nutrients during a period of stress (Proud, 2002) remains to be established; however, it could partly explain the almost absent lipogenic enzyme activity that has been reported in SAT during early lactation (McNamara et al., 1995).

\section{Adipogenesis and Lipogenesis}

A recent transcriptomics study (Sumner-Thomsen et al., 2011) provided evidence that changes in SAT gene expression during the transition period exert an important level of control over tissue function (i.e., lipogenesis, lipolysis, and remodeling). Despite a lack of direct evidence in bovine adipocytes, Kadegowda et al. (2009) found greater mRNA expression of $A C A C A$, 
FASN, DGAT1, LPIN1, and AGPAT6 in bovine mammary epithelial cells when the culture medium was supplemented with the PPAR $\gamma$ agonist rosiglitazone. Thus, we suggest from our data that expression of lipogenic genes was probably subject to PPAR $\gamma$ transcriptional regulation.

Although no carryover effects of prepartal plane of nutrition were detectable after calving for the lipogenic enzymes, overfeeding energy led to sustained upregulation of PPARG, ADIPOQ, INSIG1, INSIG2, and SCAP (Figures 3 and 4) through at least $7 \mathrm{~d}$ postpartum. Furthermore, the PPAR $\gamma$ and CEBP $\alpha$ coactivator LPIN1 (most abundant isoform in AT; Csaki and Reue, 2010) almost doubled in expression, probably as a counterregulatory mechanism to help retain an adipogenic potential (Csaki and Reue, 2010) in light of CEBPA and INSIG1 downregulation. The greater $A D I P O Q$ expression (likely driven via $\operatorname{PPAR} \gamma$ ) might have been an additional factor allowing SAT to retain insulin sensitivity as well as help dampen proinflammatory signals (Tishinsky et al., 2011) even after calving.

Together, these data seemed to suggest that adipogenic capacity in SAT (e.g., from existing stem cells or preadipocytes) was maintained despite the substantial release of long-chain FA (LCFA) into the circulation (i.e., increased blood NEFA postpartum; Table 2). It is important to note, however, that only differentiated adipocytes would be expected to accrete TAG and release NEFA during lipolysis. The fact that only a fraction of samples at -10 and $7 \mathrm{~d}$ expressed $D L K 1$ (or PREF1) suggests that the process of preadipocyte differentiation was actively taking place. The 2.5-fold increase in expression of the PPAR $\gamma$ regulator $Z F P 423$ (Gupta et al., 2010) between -10 and $7 \mathrm{~d}$ compared with $21 \mathrm{~d}$ was additional evidence, albeit at the mRNA level, that adipogenic capacity (i.e., proliferation of stem cells to preadipocytes) in SAT of postpartal cows was not entirely lost, as would be expected from classic lipogenic enzyme work (e.g., McNamara et al., 1995). In nonruminant mammals, both PPARG and ZFP423 expression (along with LPIN1) is absolutely required for AT differentiation (Rosen and MacDougald, 2006; Csaki and Reue, 2010; Gupta et al., 2010).

The holistic upregulation of most lipogenic genes (Figure 5) at $-10 \mathrm{~d}$ in response to energy overfeeding underscored the existence of a coregulatory mechanism. The importance of CEBP $\alpha$ in the regulation of adipogenesis in rodents has long been recognized. The presence of $\mathrm{CEBP} \alpha$ was required for maintaining PPAR $\gamma$ expression during adipocyte differentiation (Rosen and MacDougald, 2006). Furthermore, blunting CEBPA expression led to markedly lower expression of $P P A R G$, FABP4, GLUT4, and DGAT2 in 3T3-L1 adipocytes (Payne et al., 2010). Our data revealed an identical expression pattern of CEBPA (also INSIG1) to that of lipogenic genes in response to dietary treatment and the change in physiological state. Thus, just as for $\operatorname{PPAR} \gamma$, we propose that the presence of $\mathrm{CEBP} \alpha$ is a key component required to sustain the expression of lipogenic genes in SAT of peripartal dairy cows.

Clearly, the lack of significant change in $C E B P A$ (and also $P P A R G$ ) between 7 and $21 \mathrm{~d}$ might have curtailed the prolipogenic response because ZFP423 increased markedly during the same time frame. The presence of $\mathrm{CEBP} \alpha$ is required for acquisition of insulin sensitivity in murine adipocytes. Differentiated $\mathrm{CEBPo}^{-/-}$fat cells (induced by ectopic expression of PPAR $\gamma$ ) completely lost the ability for insulin-stimulated glucose uptake, which was due to reduced gene expression and tyrosine phosphorylation of INSR and IRS1 (Wu et al., 1999). Whether the reduced adipose IRS1-PY postpartum observed in the current study resulted from the decrease in expression of $C E B P A$ warrants further research; however, the response in CEBPA (and also ZFP423) supports the notion that some degree of insulin responsiveness was restored by 3 wk postpartum. Our data highlighted the interrelationships among transcription regulators and posttranscriptional events in regulating the overall process of adipogenesis and lipogenesis in bovine SAT.

From a mechanistic standpoint, the higher expression of ACSS2 and LDHB indicated that OVE cows had the potential to activate and channel more ruminallyderived acetate and lactate (Hood et al., 1972) from blood toward LCFA during the dry period. In addition to de novo FA synthesis, the process of uptake of preformed FA ( $L P L$ and ACSL1) and esterification (GPAM, DGAT2, and PCK1) likely contributed to TAG accretion in SAT. Although classic in vitro studies showed low activity of ACLY in ruminant AT (Ingle et al., 1972), our data indicated potentially greater glucose use for lipogenesis in OVE cows during pregnancy. The opposite was the case for lactate because expression of $L D H B$ increased markedly between 7 and $21 \mathrm{~d}$ [i.e., SAT has the potential to adapt to using nutrients (e.g., lactate) that are not preferentially used by the mammary gland for lipogenesis]. More importantly, our data suggested that $A C L Y$ is adaptable to the amount of intracellular nutrient availability and particularly dietary starch (Graugnard et al., 2010). Together, our data support previous results showing greater basal adipose esterification rates in energy-overfed as compared with restricted-fed cows prepartum (Rukkwamsuk et al., 1999).

The coordinated downregulation of lipogenic genes, especially in the OVE group, at $7 \mathrm{~d}$ may be attributed to exacerbated IR in early lactation and reduced availability of lipogenic substrates, which was deduced from 
the decrease in expression of GLUT4, PCK1, ACSS2, and IDH1. Contrary to previous work with heifers (Sumner-Thomson et al., 2011), it was remarkable that in control cows the degree of downregulation of most lipogenic genes (and also CEBPA, LPIN1, and INSIG2) was quite modest. Despite the marked upregulation of IRS1 and SREBF1 expression between 7 and $21 \mathrm{~d}$, the response was insufficient to enhance expression of most lipogenic genes and only those related with FA uptake (CD36, SLC27A1, and FABP4) were upregulated.

\section{Lipolysis: Novel Link with Adipogenesis}

The classic lipolytic pathway in response to $\beta$-adrenergic stimulation and HSL is well established (McNamara, 1991). Not until recently has accumulating evidence indicated the existence of ATGL, which is highly expressed in white AT and is primarily responsible for both basal and $\beta$-adrenergic-stimulated TAG hydrolysis (Duncan et al., 2007). The complete activation of ATGL requires binding to its activator protein ABHD5 after it dissociates from PLIN, followed by phosphorylation induced by $\beta$-adrenergic stimulation (Duncan et al., 2007). Due to the specificity or preference of its substrate (TAG), ATGL is now considered the rate-limiting enzyme of lipolysis in mammals (Duncan et al., 2007). The antilipolytic effect of insulin reduces the activity of protein kinase A (PKA) by stimulating PDE3B, which increases catabolism of cytosolic cAMP, thereby preventing phosphorylation of PLIN and effectively reversing the dissociation of PLIN and ABHD5 (Duncan et al., 2007).

Based on the known roles of ATGL and ABDH5, it was interesting that OVE cows had both slightly lower prepartal serum NEFA and higher mRNA expression of $A T G L, A B H D 5$, and $M G L L$ (the last enzyme in the lipolytic pathway). We speculate that this might be explained by 1) lower hormonal lipolytic signals prepartum;2) undiminished antilipolytic effect by insulin; and 3) greater capacity of AT from OVE cows to re-esterify the circulating NEFA. Thus, despite the greater mRNA expression of $A T G L$ and $A B H D 5$, lipolysis prepartum was still tightly controlled in OVE cows. More importantly, however, our data are the first to underscore the existence (as in nonruminants) of a coordinated response among adipogenesis, lipogenesis, and lipolysis, with a strong degree of transcriptional regulation likely via PPAR $\gamma$ and CEBP $\alpha$. In fully-differentiated 3T3-L1 adipocytes, both $A T G L$ mRNA and protein expression were induced by PPAR $\gamma$ agonists in a dose- and timedependent manner (Kershaw et al., 2007). The same response of $A T G L$ was observed in white AT of either lean or obese mice following oral treatment with rosiglitazone (Kershaw et al., 2007).
Although modest, the postpartal decrease in $A T G L$ and ABHD5 mRNA expression in both groups agrees with the lower ATGL protein expression in early lactating as compared with late pregnant dairy cows (Koltes and Spurlock, 2011). Both mRNA and protein expression of $A T G L$ in AT were reduced in individuals with obesity-induced IR compared with insulin-sensitive subjects (Jocken et al., 2007). In OVE cows, however, the greater prepartal $A T G L, A B H D 5$, and $M G L L$ was in part due to greater PPARG and $C E B P A$, which in human adipocytes regulates expression of these genes (Lo et al., 2011; i.e., substantially-positive energy balance not only promotes lipogenic gene expression but also the expression of $A T G L)$. This suggestion also was supported by the parallel postpartal decrease of $A T G L$ and ABHD5 mRNA expression and IRS1-PY [Figure 2; i.e., from a mechanistic standpoint, insulin sensitivity (conferred in part via PPAR $\gamma$ and $\mathrm{CEBP} \alpha$ ) is probably required to maintain $A T G L$ expression in bovine adipocytes]. Similar to adipogenesis/lipogenesis, energy overfeeding (probably via CEBP $\alpha$ and PPAR $\gamma$ ) likely allows for SAT remodeling via lipolysis; however, the lower expression of $P C K 1$ and $L D H B$ postpartum hindered the production of glycerol-3-phosphate and allowed for LCFA to exit the cell into the circulation (i.e., increase NEFA in serum). The gradual increase in $A D R B 2$ expression and the longitudinal NEFA profile after $7 \mathrm{~d}$ (Supplemental Figure 4, available online at http://www.journalofdairyscience.org/) seem to support this idea.

The pattern of expression we observed for $G H R$, $A D R B 2, H S L$, and NR3C1 suggested that dietary OVE did not alter sensitivity of SAT to lipolytic stimulation postpartum (e.g., via norepinephrine or cortisol). Growth hormone action on AT antagonizes insulin by amplifying the lipolytic response to $\beta$-adrenergic signals and inhibiting lipogenesis (Etherton and Bauman, 1998). Rhoads et al. (2004) reported that the abundance of GHR protein in SAT of dairy cows decreased in parallel with the decrease in plasma insulin concentration from late pregnancy $(-28 \mathrm{~d})$ to early lactation $(10 \mathrm{~d})$. However, administration of exogenous insulin increased adipose GHR protein expression both in late pregnancy and early lactation (Rhoads et al., 2004). Taken together these data seem to support the greater GHR expression we observed with OVE. In 3T3 L1 adipocytes, GH exerts an antilipolytic effect by converging on the intracellular insulin signaling pathway through tyrosine phosphorylation of IRS isoforms (Yamauchi et al., 1998). Thus, the greater GHR expression in OVE may have served to reduce prepartal lipolysis.

The degree of change in expression we observed postpartum for $A D R B 2$ was lower than reported previously at 30 compared with $-30 \mathrm{~d}$ (Sumner and McNamara, 


\begin{tabular}{|c|c|c|c|c|c|}
\hline Prepartum & Insulin & IR & Postpartum & Insulin & IR \\
\hline$-10 \mathrm{~d}$ vs. $7 \mathrm{~d}$ & 1. & 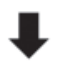 & $7 \mathrm{~d}$ vs. $-10 \mathrm{~d}$ & 7 & 1 \\
\hline OVE vs. CON & 1 & E & OVE vs. CON & E & 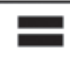 \\
\hline
\end{tabular}

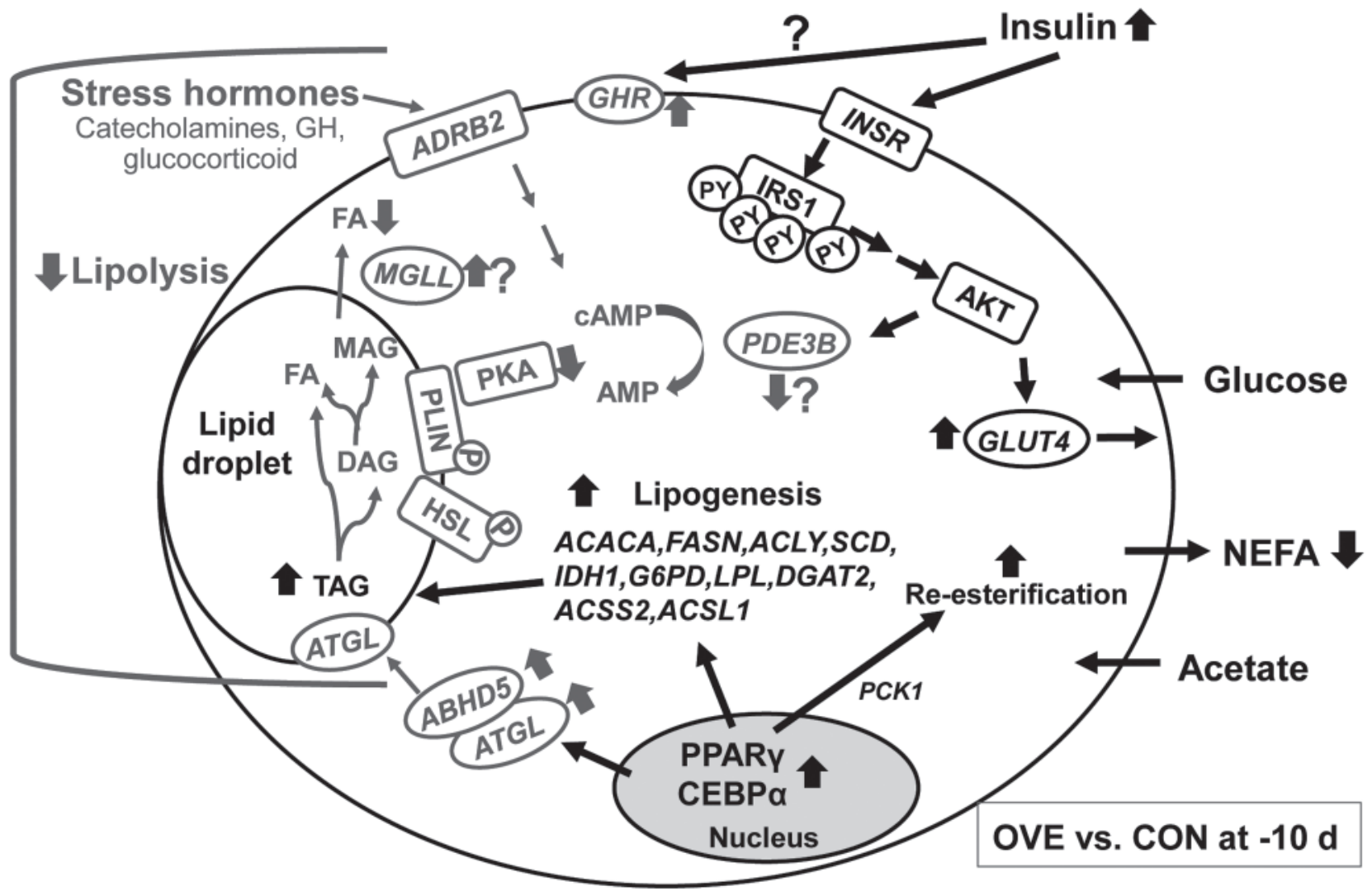

Figure 7. Relative changes in insulin and insulin resistance (IR) in response to plane of dietary energy during the transition period (table insert) and putative regulatory network of pathways involved in metabolism of subcutaneous adipose tissue prepartum. The predominant pathways are depicted in black, whereas the subordinate pathways are in gray. OVE = overfeeding of a moderate-energy diet; CON = controlled-energy diet to meet energy requirements. Legend: equal sign $=$ no difference; arrow shape $=$ increase or decrease; dashed line arrow $=$ transcriptional regulation; solid line arrow $=$ stimulation or activation of a pathway, transport direction of metabolites; spherical shape $=$ gene studied; square shape $=$ protein product of gene. $\mathrm{ADRB} 2=\beta-2$ adrenergic receptor; GHR $=$ growth hormone $(\mathrm{GH})$ receptor; INSR $=$ insulin receptor; IRS1 $=$ insulin receptor substrate $1 ; \mathrm{PY}=$ phosphorylation; $\mathrm{AKT}=\mathrm{v}$-akt murine thymoma viral oncogene homolog; $\mathrm{PDE} 3 \mathrm{~B}=$ phosphodiesterase $3 \mathrm{~B}$; GLUT4 = glucose transporter 4; MGLL = monoglyceride lipase; PKA = protein kinase A; PLIN = perilipin; HSL = hormone-sensitive lipase; ATGL $=$ adipose triglyceride lipase MAG $=$ monoacylglycerol; DAG = diacylglycerol; $\mathrm{TAG}=$ triglyceride; $\mathrm{ABHD} 5=$ abhydrolase domain containing 5; $\mathrm{PPAR} \gamma=$ peroxisome proliferator-activated receptor $\gamma ; \mathrm{CEBP} \alpha=\mathrm{CCAAT} /$ enhancer-binding protein $\alpha ; \mathrm{ACACA}=$ acetyl-CoA carboxylase $\alpha ; \mathrm{FASN}=\mathrm{FA}$ synthase; $\mathrm{ACLY}=\mathrm{ATP}$ citrate lyase SCD = stearoyl-CoA desaturase; IDH1 = isocitrate dehydrogenase $1 ;$ G6PD = glucose-6-phosphate dehydrogenase $; \mathrm{LPL}=$ lipoprotein lipase; DGAT2 = diacylglycerol $O$-acyltransferase $2 ; \mathrm{ACSS} 2=$ acyl-CoA synthetase short-chain family member 2 ; ACSL1 = acyl-CoA synthetase long-chain family member 1.

2007). Furthermore, we found no change in $H S L$ or PLIN1 due to stage of lactation as reported previously (Sumner and McNamara, 2007) and the decrease in PLIN2 was modest even by $21 \mathrm{~d}$. The sympathetic nervous system in bovine AT might not be as active during lactation as in rats (McNamara and Murray, 2001). The fact that GHR was still greater early postpartum coupled with previous data showing greater postpartal blood GH due to prepartal OVE (Khan et al., 2011) seems to argue against the concept of altered sensitivity. However, the postpartal difference in blood NEFA between OVE and CON was minor and nonsignificant (Supplemental Figure 4, available online at http:// www.journalofdairyscience.org/).

A potentially important point that is often overlooked when focusing strictly on lipolysis or lipogenesis is that both processes likely are tightly controlled. This was exemplified recently with the discovery that $\mathrm{CEBP} \alpha$ 
controls transcription of both lipogenic and lipolytic genes in AT (Lo et al., 2011). In the context of posttranscriptional control, it should be noted that, despite unchanged HSL protein expression, Koltes and Spurlock (2011) found increased phosphorylation of HSL in SAT early postcalving compared with late pregnancy, which supported the notion of greater postparturient $\beta$-adrenergic-stimulated lipolysis. Clearly, mechanistic regulation occurs at multiple levels and our and previous data allow for a better description of the events controlling blood NEFA in peripartal cows (Holtenius et al., 2003; Dann et al., 2006; Janovick et al., 2011).

\section{CONCLUSIONS}

In the current study, close-up energy overfeeding had no benefit on milk production or component yields, yet resulted in greater change between pre- and postpartal NEFA concentration, which underscored the lower efficiency of such a feeding strategy. Such results are consistent with the recent findings from 3 studies in our group, in which the same dietary treatments with larger groups of animals were used (Richards et al., 2009; Khan et al., 2011; Vasquez et al., 2011). Contrary to our hypothesis, overfeeding of the moderate energy diet facilitated rather than compromised the pathway of insulin signaling in SAT particularly during late pregnancy (Figure 7). The result was a robust upregulation of the entire repertoire of adipogenic regulators and lipogenic enzymes (Figure 7), which for the former (e.g., PPARG) lasted through at least the first week postpartum. In fact, basal lipolysis was part of the pro-adipogenic/lipogenic response induced by energy overfeeding and might have been under control of both PPAR $\gamma$ and CEBP $\alpha$ even after calving (Figure 7 ). The fact that the enzymes controlling stimulated lipolysis (HSL, PLIN1, and PLIN2) are apparently not regulated by $\mathrm{PPAR} \gamma$ or $\mathrm{CEBP} \alpha$ and that their change in expression after calving was modest suggested that bovine SAT lipolytic control around parturition from a transcriptional standpoint is primarily at the level of basal lipolysis (as in nonruminants). The role of ATGL in controlling lipolysis after calving might also extend to stimulated lipolysis (i.e., once this pathway is activated, greater abundance of ATGL could promote binding to ABHD5, thus enhancing lipolytic activity in SAT). Our data revealed an important link between basal lipolysis and adipogenesis/lipogenesis (Figure 7).

Despite the decrease in serum insulin concentration and insulin sensitivity assessed via IRS1-PY (Figure 7), overall, the data seemed to highlight the fact that negative energy balance after calving does not necessarily correlate with a reduction in insulin-responsive, adipogenic, or lipogenic gene expression in SAT. This idea was further underscored by the modest response observed after calving in cows fed to meet energy requirements prepartum. Therefore, although our data seemed to explain in part the almost complete loss of lipogenic enzyme activity in early lactation (McNamara et al. 1995) it also highlighted that nutrient availability (e.g., acetate) is a major determinant of SAT remodeling/accretion early postpartum. We speculate that postpartal management strategies that could enhance nutrient (e.g., acetate, glucose, and AA) availability to adipose tissue might be effective in accelerating its replenishment.

Our study highlighted a pivotal role of PPAR $\gamma$ and $\mathrm{CEBP} \alpha$ as major transcriptional regulators of lipogenic gene expression and basal lipolysis during the peripartal period. Because signs of restored insulin responsiveness (e.g., upregulation of IRS1, INSIG2, SREBF1, ZFP423, and CD36) were apparent as early as $3 \mathrm{wk}$ postpartum, identifying specific nutrients capable of activating $\mathrm{PPAR} \gamma$ and $\mathrm{CEBP} \alpha$ specifically in adipose after calving might prove useful in terms of accelerating adipose tissue replenishment.

\section{REFERENCES}

Bauman, D. E., and W. B. Currie. 1980. Partitioning of nutrients during pregnancy and lactation: A review of mechanisms involving homeostasis and homeorhesis. J. Dairy Sci. 63:1514-1529.

Bell, A. W. 1995. Regulation of organic nutrient metabolism during transition from late pregnancy to early lactation. J. Anim. Sci. 73:2804-2819.

Bionaz, M., and J. J. Loor. 2008. Gene networks driving bovine milk fat synthesis during the lactation cycle. BMC Genomics 9:366387.

Csaki, L. S., and K. Reue. 2010. Lipins: Multifunctional lipid metabolism proteins. Annu. Rev. Nutr. 30:257-272.

Dann, H. M., N. B. Litherland, J. P. Underwood, M. Bionaz, A. D'Angelo, J. W. McFadden, and J. K. Drackley. 2006. Diets during far-off and close-up dry periods affect periparturient metabolism and lactation in multiparous cows. J. Dairy Sci. 89:3563-3577.

Drackley, J. K., T. R. Overton, and G. N. Douglas. 2001. Adaptations of glucose and long-chain fatty acid metabolism in liver of dairy cows during the periparturient period. J. Dairy Sci. 84(E. Suppl.):E100-E112.

Duncan, R. E., M. Ahmadian, K. Jaworski, E. Sarkadi-Nagy, and H. S. Sul. 2007. Regulation of lipolysis in adipocytes. Annu. Rev. Nutr. 27:79-101.

Dutton, S., and P. Trayhurn. 2008. Regulation of angiopoietin-like protein 4/fasting-induced adipose factor (Angptl4/FIAF) expression in mouse white adipose tissue and 3T3-L1 adipocytes. Br. J. Nutr. 100:18-26.

Esposito, D. L., Y. Li, A. Cama, and M. J. Quon. 2001. Tyr ${ }^{612}$ and $\mathrm{Ty}^{632}$ in human insulin receptor substrate-1 are important for full activation of insulin-stimulated phosphatidylinositol 3-kinase activity and translocation of GLUT4 in adipose cells. Endocrinology $142: 2833-2840$.

Etherton, T. D., and D. E. Bauman. 1998. Biology of somatotropin in growth and lactation of domestic animals. Physiol. Rev. 78:745761.

Foufelle, F., and P. Ferré. 2002. New perspectives in the regulation of hepatic glycolytic and lipogenic genes by insulin and glucose: A 
role for the transcription factor sterol regulatory element binding protein-1c. Biochem. J. 366:377-391.

Franck, N., A. Gummesson, M. Jernås, C. Glad, P.-A. Svensson, G. Guillot, M. Rudemo, F. H. Nyström, L. M. Carlsson, and B. Olsson. 2011. Identification of adipocyte genes regulated by caloric intake. J. Clin. Endocrinol. Metab. 96:E413-E418.

Graugnard, D. E., L. L. Berger, D. B. Faulkner, and J. J. Loor. 2010 High-starch diets induce precocious adipogenic gene network upregulation in longissimus lumborum of early-weaned Angus cattle. Br. J. Nutr. 103:953-963.

Guesnet, P. M., M. J. Massoud, and Y. Demarne. 1991. Regulation of adipose tissue metabolism during pregnancy and lactation in the ewe: The role of insulin. J. Anim. Sci. 69:2057-2065.

Gupta, R. K., Z. Arany, P. Seale, R. J. Mepani, L. Ye, H. M. Conroe, Y. A. Roby, H. Kulaga, R. R. Reed, and B. M. Spiegelman. 2010. Transcriptional control of preadipocyte determination by Zfp423. Nature 464:619-623.

Holtenius, K., S. Agenäs, C. Delavaud, and Y. Chilliard. 2003. Effects of feeding intensity during the dry period. 2. Metabolic and hormonal responses. J. Dairy Sci. 86:883-891.

Hood, R. L., E. H. Thompson, and C. E. Allen. 1972. The role of acetate, propionate and glucose as substrates for lipogenesis in bovine tissues. Int. J. Biochem. 3:598-606.

Ingle, D. L., D. E. Bauman, and U. S. Garrigus. 1972. Lipogenesis in the ruminant: in vivo site of fatty acid synthesis in sheep. J. Nutr. 102:617-623

Janovick, N. A., Y. R. Boisclair, and J. K. Drackley. 2011. Prepartum dietary energy intake affects metabolism and health during the periparturient period in primiparous and multiparous Holstein cows. J. Dairy Sci. 94:1385-1400.

Janovick, N. A., and J. K. Drackley. 2010. Prepartum dietary management of energy intake affects postpartum intake and lactation performance by primiparous and multiparous Holstein cows. J. Dairy Sci. 93:3086-3102.

Jocken, J. W., D. Langin, E. Smit, W. H. Saris, C. Valle, G. B. Hul, C. Holm, P. Arner, and E. E. Blaak. 2007. Adipose triglyceride lipase and hormone-sensitive lipase protein expression is decreased in the obese insulin-resistant state. J. Clin. Endocrinol. Metab. 92:2292-2299.

Kadegowda, A. K., M. Bionaz, L. S. Piperova, R. A. Erdman, and J. J. Loor. 2009. Peroxisome proliferator-activated receptor- $\gamma$ activation and long-chain fatty acids alter lipogenic gene networks in bovine mammary epithelial cells to various extents. J. Dairy Sci. 92:4276-4289.

Kahn, C. R. 1978. Insulin resistance, insulin insensitivity, and insulin unresponsiveness: A necessary distinction. Metabolism 27:18931902

Kershaw, E. E., M. Schupp, H. P. Guan, N. P. Gardner, M. A. Lazar, and J. S. Flier. 2007. PPAR $\gamma$ regulates adipose triglyceride lipase in adipocytes in vitro and in vivo. Am. J. Physiol. Endocrinol. Metab. 293:E1736-E1745

Khan, J., D. Graugnard, D. H. Keisler, B. J. Bradford, L. H. Mamedova, J. K. Drackley, and J. J. Loor. 2011. Hepatokine, growth hormone, and PPAR $\alpha$-regulated gene network expression in liver of peripartal cows fed two levels of dietary energy prepartum. J. Dairy Sci. 94(E-Suppl. 1):779.

Koltes, D. A., and D. M. Spurlock. 2011. Coordination of lipid dropletassociated proteins during the transition period of Holstein dairy cows. J. Dairy Sci. 94:1839-1848.

Lo, K. A., M. K. Bauchmann, A. P. Baumann, C. J. Donahue, M. A. Thiede, L. S. Hayes, S. A. des Etages, and E. Fraenkel. 2011. Genome-wide profiling of H3K56 acetylation and transcription factor binding sites in human adipocytes. PLoS ONE 6:e19778.

McNamara, J. P. 1991. Regulation of adipose tissue metabolism in support of lactation. J. Dairy Sci. 74:706-719.

McNamara, J. P., J. H. Harrison, R. L. Kincaid, and S. S. Waltner. 1995. Lipid metabolism in adipose tissue of cows fed high fat diets during lactation. J. Dairy Sci. 78:2782-2796.

McNamara, J. P., and C. E. Murray. 2001. Sympathetic nervous system activity in adipose tissues during pregnancy and lactation of the rat. J. Dairy Sci. 84:1382-1389.
NRC. 2001. Nutrient Requirements for Dairy Cattle. 7th rev. ed. ed. National Academy Press, Washington, DC.

Nye, C., J. Kim, S. C. Kalhan, and R. W. Hanson. 2008. Reassessing triglyceride synthesis in adipose tissue. Trends Endocrinol. Metab. 19:356-361.

Ogihara, T., B. C. Shin, M. Anai, H. Katagiri, K. Inukai, M. Funaki, Y. Fukushima, H. Ishihara, K. Takata, M. Kikuchi, Y. Yazaki, Y. Oka, and T. Asano. 1997. Insulin receptor substrate (IRS)-2 is dephosphorylated more rapidly than IRS-1 via its association with phosphatidylinositol 3-kinase in skeletal muscle cells. J. Biol. Chem. 272:12868-12873.

Oikawa, S., and G. R. Oetzel. 2006. Decreased insulin response in dairy cows following a four-day fast to induce hepatic lipidosis. J. Dairy Sci. 89:2999-3005.

Payne, V. A., W.-S. Au, C. E. Lowe, S. M. Rahman, J. E. Friedman, S. O'Rahilly, and J. J. Rochford. 2010. C/EBP transcription factors regulate SREBP1c gene expression during adipogenesis. Biochem. J. $425: 215-223$.

Petterson, J. A., F. R. Dunshea, R. A. Ehrhardt, and A. W. Bell. 1993 Pregnancy and undernutrition alter glucose metabolic responses to insulin in sheep. J. Nutr. 123:1286-1295.

Proud, C. G. 2002. Regulation of mammalian translation factors by nurtrients. Eur. J. Biochem. 269:5338-5349.

Rhoads, R. P., J. W. Kim, B. J. Leury, L. H. Baumgard, N. Segoale, S. J. Frank, D. E. Bauman, and Y. R. Boisclair. 2004. Insulin increases the abundance of the growth hormone receptor in liver and adipose tissue of periparturient dairy cows. J. Nutr. 134:1020-1027.

Richards, B. F., N. A. Janovick, K. M. Moyes, D. E. Beever, and J. K. Drackley. 2009. Comparison of a controlled-energy high-fiber diet fed throughout the dry period to a two-stage far-off and close-up dietary strategy. J. Dairy Sci. 92(E-Suppl. 1):E140. (Abstr.)

Rosen, E. D., and O. A. MacDougald. 2006. Adipocyte differentiation from the inside out. Nat. Rev. Mol. Cell Biol. 7:885-896.

Rukkwamsuk, T., T. Wensing, and M. J. Geelen. 1998. Effect of overfeeding during the dry period on regulation of adipose tissue metabolism in dairy cows during the periparturient period. J. Dairy Sci. 81:2904-2911.

Rukkwamsuk, T., T. Wensing, and M. J. Geelen. 1999. Effect of overfeeding during the dry period on the rate of esterification in adipose tissue of dairy cows during the periparturient period. J. Dairy Sci. 82:1164-1169.

Sadri, H., R. M. Bruckmaier, H. R. Rahmani, G. R. Ghorbani, I. Morel, and H. A. van Dorland. 2010. Gene expression of tumour necrosis factor and insulin signaling-related factors in subcutaneous adipose tissue during the dry period and in early lactation in dairy cows. J. Anim. Physiol. Anim. Nutr. (Berl.) 94:e194-e202.

Saltiel, A. R., and C. R. Kahn. 2001. Insulin signaling and the regulation of glucose and lipid metabolism. Nature 414:799-806.

Schoenberg, K. M., R. M. Ehrhardt, and T. R. Overton. 2012. Effects of plane of nutrition and feed deprivation on insulin responses in dairy cattle during late gestation. J. Dairy Sci. 95:670-682.

Sekiya, M., N. Yahagi, T. Matsuzaka, Y. Takeuchi, Y. Nakagawa, H. Takahashi, H. Okazaki, Y. Iizuka, K. Ohashi, T. Gotoda, S. Ishibashi, R. Nagai, T. Yamazaki, T. Kadowaki, N. Yamada, J. Osuga, and H. Shimano. 2007. SREBP-1-independent regulation of lipogenic gene expression in adipocytes. J. Lipid Res. 48:1581-1591.

Sesti, G., M. Federici, M. L. Hribal, D. Lauro, P. Sbraccia, and R Lauro. 2001. Defects of the insulin receptor substrate (IRS) system in human metabolic disorders. FASEB J. 15:2099-2111.

Sevillano, J., J. de Castro, C. Bocos, E. Herrera, and M. P. Ramos. 2007. Role of insulin receptor substrate-1 serine 307 phosphorylation and adiponectin in adipose tissue insulin resistance in late pregnancy. Endocrinology 148:5933-5942.

Sumner, J. M., and J. P. McNamara. 2007. Expression of lipolytic genes in the adipose tissue of pregnant and lactating Holstein dairy cattle. J. Dairy Sci. 90:5237-5246.

Sumner-Thomson, J. M., J. L. Vierck, and J. P. McNamara. 2011 Differential expression of genes in adipose tissue of first-lactation dairy cattle. J. Dairy Sci. 94:361-369.

Tishinsky, J. M., D. W. Ma, and L. E. Robinson. 2011. Eicosapentaenoic acid and rosiglitazone increase adiponectin in an additive and 
PPAR $\gamma$-dependent manner in human adipocytes. Obesity (Silver Spring) 19:262-268.

Vandesompele, J., K. De Preter, F. Pattyn, B. Poppe, N. Van Roy, A. De Paepe, and F. Speleman. 2002. Accurate normalization of realtime quantitative RT-PCR data by geometric averaging of multiple internal control genes. Genome Biol. 3:RESEARCH0034.

Vasquez, J. A., K. L. Perfield, H. B. Green, and J. K. Drackley. 2011. Effects of close-up dietary energy strategy and prepartal dietary monensin on production and metabolism in Holstein cows. J. Dairy Sci. 94:690. (Abstr.)

Vernon, R. G., R. A. Clegg, and D. J. Flint. 1981. Metabolism of sheep adipose tissue during pregnancy and lactation. Biochem. J. 200:307-314.

Vernon, R. G., and E. Taylor. 1988. Insulin, dexamethasone and their interactions in the control of glucose metabolism in adipose tissue from lactating and nonlactating sheep. Biochem. J. 256:509-514.
Wu, Z., E. D. Rosen, R. Brun, S. Hauser, G. Adelmant, A. E. Troy, C. McKeon, G. J. Darlington, and B. M. Spiegelman. 1999. Cross-regulation of $\mathrm{C} / \mathrm{EBP} \alpha$ and $\mathrm{PPAR} \gamma$ controls the transcriptional pathway of adipogenesis and insulin sensitivity. Mol. Cell 3:151-158.

Yamauchi, T., Y. Kaburagi, K. Ueki, Y. Tsuji, G. R. Stark, I. M. Kerr, T. Tsushima, Y. Akanuma, I. Komuro, K. Tobe, Y. Yazaki, and T. Kadowaki. 1998. Growth hormone and prolactin stimulate tyrosine phosphorylation of insulin receptor substrate- $1,-2$, and -3 , their association with p85 phosphatidylinositol 3-kinase (PI3-kinase), and concomitantly PI3-kinase activation via JAK2 kinase. J. Biol. Chem. 273:15719-15726. 